\title{
Antibacterial Discovery and Development: From Gene to Product and Back
}

\author{
Victor Fedorenko, ${ }^{1}$ Olga Genilloud, ${ }^{2}$ Liliya Horbal, ${ }^{1}$ Giorgia Letizia Marcone, ${ }^{3,4}$ \\ Flavia Marinelli, ${ }^{3,4}$ Yossi Paitan, ${ }^{5}$ and Eliora Z. Ron ${ }^{6,7}$ \\ ${ }^{1}$ Department of Genetics and Biotechnology, Ivan Franko National University of Lviv, Lviv 79005, Ukraine \\ ${ }^{2}$ Fundación MEDINA, Health Sciences Technology Park, 18016 Granada, Spain \\ ${ }^{3}$ Department of Biotechnology and Life Sciences, University of Insubria, 21100 Varese, Italy \\ ${ }^{4}$ The Protein Factory, Interuniversity Centre Politecnico di Milano, ICRM CNR Milano, and University of Insubria, 21100 Varese, Italy \\ ${ }^{5}$ Clinical Microbiology Laboratory, Meir Medical Center, 44281 Kfar Saba, Israel \\ ${ }^{6}$ Department of Molecular Microbiology and Biotechnology, Tel Aviv University, 6997801 Tel Aviv, Israel \\ ${ }^{7}$ Galilee Research Institute (MIGAL), 11016 Kiryat Shmona, Israel
}

Correspondence should be addressed to Flavia Marinelli; flavia.marinelli@uninsubria.it

Received 30 October 2014; Revised 30 December 2014; Accepted 13 January 2015

Academic Editor: Metin Guru

Copyright (C) 2015 Victor Fedorenko et al. This is an open access article distributed under the Creative Commons Attribution License, which permits unrestricted use, distribution, and reproduction in any medium, provided the original work is properly cited.

\begin{abstract}
Concern over the reports of antibiotic-resistant bacterial infections in hospitals and in the community has been publicized in the media, accompanied by comments on the risk that we may soon run out of antibiotics as a way to control infectious disease. Infections caused by Enterococcus faecium, Staphylococcus aureus, Klebsiella species, Clostridium difficile, Acinetobacter baumannii, Pseudomonas aeruginosa, Escherichia coli, and other Enterobacteriaceae species represent a major public health burden. Despite the pharmaceutical sector's lack of interest in the topic in the last decade, microbial natural products continue to represent one of the most interesting sources for discovering and developing novel antibacterials. Research in microbial natural product screening and development is currently benefiting from progress that has been made in other related fields (microbial ecology, analytical chemistry, genomics, molecular biology, and synthetic biology). In this paper, we review how novel and classical approaches can be integrated in the current processes for microbial product screening, fermentation, and strain improvement.
\end{abstract}

\section{Introduction}

Antibacterial therapy has saved millions of lives and considerably reduced the rate of premature death from bacterial infections. These achievements led to the assumption that pathogenic bacteria and the high mortality due to infectious diseases would be a thing of the past. Unfortunately, soon after the introduction of antibiotics, reports concerning the emergence of resistance started to accumulate. Antibiotic resistance mechanisms, which appear de novo or are transmitted among bacteria, have been well studied and described in many reviews. These include detoxification of antibiotic molecules and mutations in the designated target or, as described recently, are mediated by population-level resistance mechanisms [1]. It is now apparent that interspecies and intraspecies horizontal gene transfer of both Gram-negative and Gram-positive bacteria represent the dominant process by which bacteria become multiresistant. The selective pressure of antimicrobial use in hospitals, in communities, and in agriculture comprises the engine driving this process. Nowadays we are aware that bacterial resistance to all currently used antibiotics has emerged for both Gram-positive and Gram-negative bacteria. This threatening situation urgently calls for a concerted international effort among governments, the pharmaceutical industry, biotechnology companies, and the academic world to react and support the development of new antibacterial agents. One example of such initiative effort is the Infectious Diseases Society of America (IDSA) call to develop 10 new systemic antibacterial drugs by 2020 [2] by targeting drug development against both Gram-positive and Gram-negative bacteria. Unless serious action is taken, the acute and dangerous situation that exists today may send 
us back to the preantibiotic era, when there was no cure for bacterial infections. If this happens, the prophecy of Louis Pasteur will be fulfilled and "microbes will have the last word."

\section{Medical Needs for Novel Antibacterials}

Multidrug-resistant bacterial infections represent a major public health burden, not only in terms of morbidity and mortality, but also in increased expenses for managing patients and implementing extensive infection control measures. Mortality due to multidrug-resistant bacterial infections is high. In 2002 it was reported that 1.7 million healthcare-associated infections occur each year in American hospitals and were associated with about 99,000 deaths [3]. This represents a huge increase from a previous estimation, which reported that in 1992 about 13,300 people died from hospitalacquired infection [4]. It is estimated that in the EU, Iceland, and Norway about 37,000 patients die as a direct result of a hospital-acquired infection each year; an additional 111,000 die as an indirect result of hospital-acquired infection [5]; and about 25,000 patients die from a multidrug-resistant bacterial infection.

Presently, the most frequent multidrug resistance (MDR) bacteria are Enterococcus faecium, Staphylococcus aureus, Klebsiella pneumoniae, Acinetobacter baumannii, Pseudomonas aeruginosa, and Enterobacter spp. which therefore were termed "ESKAPE" after initially being reported [6], with several reports adding Clostridium difficile or other Enterobacteriaceae [7]. Gram-positive pathogens, such as Staphylococcus, Streptococcus, Enterococcus, and Clostridium, account for a large proportion of serious infections worldwide. An increasing percentage of such Gram-positive isolates exhibit reduced susceptibility to first-line therapies [8-10], resulting in poor clinical outcomes in both community and hospital settings [10-13]; this has a significant impact on overall healthcare utilization and costs $[10,11]$. Staphylococcus aureus and Enterococcus spp. were found to be among the most commonly isolated pathogens in the hospital environment, and being frequently resistant to multiple drugs complicates therapy. The representative hospital "superbugs," methicillinresistant $S$. aureus (MRSA) and vancomycin-resistant enterococci (VRE), frequently attract mass-media attention and, in many countries, pressure is increasing to reduce MRSA and VRE infection rates. Resistance to anti-MRSA and antiVRE drugs is uncommon; however, infections by MRSA strains resistant to glycopeptides, daptomycin, or linezolid (common anti-MRSA drugs) and by VRE strains resistant to daptomycin or linezolid (common anti-VRE drugs) are increasingly being reported, including reports of transferable resistance mechanism to these drugs among staphylococci and enterococci. In addition, reports regarding the emergence and spread of virulent clones of MRSA and Clostridium difficile in the community and in hospitals, respectively, have been published often. Moreover, multidrug-resistant Streptococcus pneumonia clones are currently considered major community pathogens in many parts of the world, although they are being challenged by new conjugate vaccines.
Although the prevalence of Gram-negative bacteria is currently somewhat lower than that of Gram-positive bacteria, it is well recognized that Gram-negative MDR infections are emerging as a threat to hospitalized patients with a significant impact on length of hospitalization, mortality, and cost $[14,15]$. These include multiresistant nonfermenters, such as Pseudomonas aeruginosa and Acinetobacter baumannii, or multiresistant, extended-spectrum $\beta$-lactamase-producing Enterobacteriaceae and more recently carbapenem-resistant Enterobacteriaceae (CRE) of different types. Emerging resistance is due to the spread of the Klebsiella pneumoniae carbapenemase (KPC) and to the novel New Delhi metallo- $\beta$ lactamase (NDM-1). The rising crisis of multidrug-resistant Gram-negative bacteria has prompted the use of salvage therapy with colistin, an older polymyxin known to be neurotoxic and nephrotoxic $[16,17]$. However, there are already reports describing isolates of several Gram-negative bacteria that are resistant to all available antibiotics, including polymyxins $[18,19]$.

\section{Natural Product Discovery: The Screening Ingredients to Exploit Microbial Diversity}

Despite the pharmaceutical sector's lack of interest in addressing the topic in the last decade, microbial products continue to represent one of the most interesting sources for the discovery of novel antibacterials today and research in the field is currently benefiting from progress that has been made in other related fields (microbial ecology, metagenomics, metabolomics, or synthetic biology), fields which have provided a deeper understanding of the microbiome and thus the development of new tools to foster the discovery of novel compounds. Among living organisms, microorganisms (actinobacteria, cyanobacteria, myxobacteria, and fungi) represent one of the most prolific sources for the production of antibiotics. For decades, exploitation of their specialized (commonly termed secondary) metabolism has guaranteed the discovery of novel antibiotics and other compounds with unprecedented chemical characteristics and biological properties that do not exist in the screening libraries of synthetic compounds $[20,21]$. In this section, we examine the current trends in microbial product screening for discovering novel antibiotics. A flow diagram showing the overall screening operation is reported in Figure 1.

3.1. Microbial Product Libraries. Microbial natural product libraries rely on the quality and diversity of novel microbial strains and the approaches used to exploit their metabolic diversity. Access to microbial diversity traditionally focused on intensive sampling and isolation using general methods from a wide range of geographical locations and habitats, with recurrent isolation and screening of the predominant species and a low probability of isolating novel compounds. Although estimates for the potential production of unknown novel molecules by Streptomyces spp. [22] were high, the reality is that species spread widely in different environments produce the same well-known and structurally related antibacterial molecules. Current approaches oriented to 


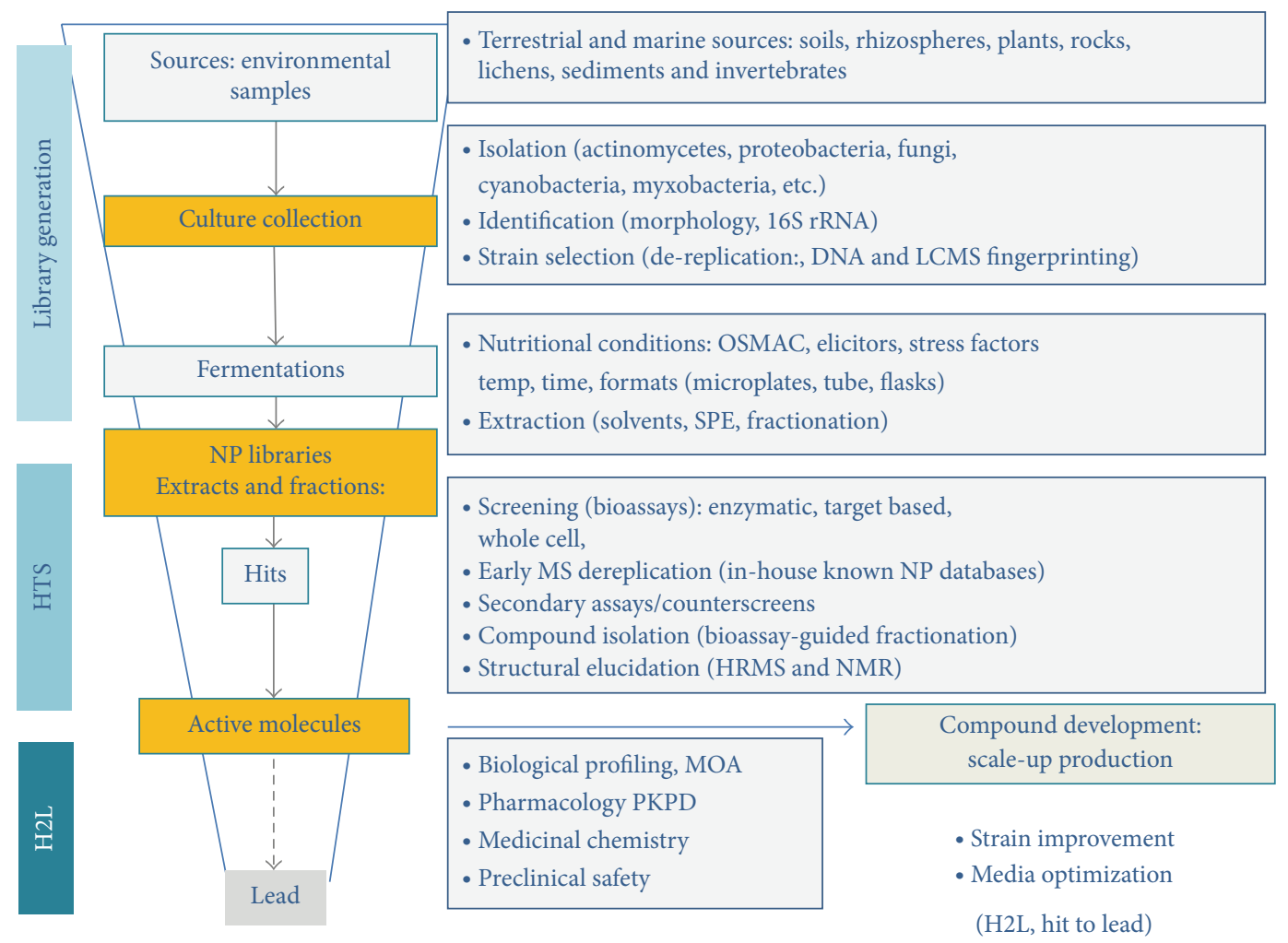

FIGURE 1: Early stages of antibiotic discovery from microbial product libraries.

discovering novel molecules mostly aim to target specific and minor microbial communities in unique or underexplored environments, including specific terrestrial niches, plant host-microbe associations, and marine environments. Environmental conditions comprise strong selecting factors and the distribution of some microbial species, even in highly occurring taxa, presents biogeographic patterns determined by microenvironmental conditions that can be translated into novel compounds. Many research groups have recently emphasized the exploration of untapped microbial communities that are associated with rhizospheres, plant endophytes, lichens, endolithic microbial communities, insect parasites, and endosymbionts and marine sediments and invertebrates. These approaches have favored the isolation of novel microbial communities potentially producing novel chemical scaffolds [23-27]. The search for novel sources has been combined with the use of novel isolation methods targeting the cultivation of species underrepresented or previously not cultivated under laboratory conditions [28-32]. Most of these methods are focused on selective isolation of the members of minor occurring taxa by using poor nutritional media devoid of carbon sources, subinhibitory concentrations of antibiotics that might favor the development of slow-growing representatives of these microbial communities after weeks of incubation, alternative gelling substrates to agar shown to prevent the growth of some microbial groups in laboratory conditions, in situ incubation chambers, or isolating endophytes that germinate directly on the substrate using humid chambers or by surface sterilization.
3.2. Tools for Strain Selection. Strain selection criteria are essential for building a strain collection and ensure the uniqueness of the isolates and that the widest microbial diversity is represented. Phenetic and molecular tools that can be applied hierarchically on the large numbers of isolates normally recovered from environmental samples have been intensively developed. These can include a simple morphological characterization of the growth and sporulating characteristics of actinomycetes and filamentous fungi at the macroscopic and microscopic levels, allowing preliminary assignment to a taxonomic group that can be complemented with the ribosomal gene sequencing of isolates in a large proportion of the cases. Partial ribosomal rDNA sequencing is frequently used to confirm the taxonomic affiliation and to assess in molecular data the microbial diversity and individual phylogenetic relationships within strains in a collection. The existing intraspecies heterogeneity in microbial taxa cannot be resolved in phylogenetic inner branches, which require the introduction of additional fingerprinting tools for selection. Other methods currently used can include the application of high-throughput chemotaxonomic profiling methods such as those based on the whole-cell fatty acid composition [33] and the use of MALDI-TOF MS protein profiles, a promising alternative to conventional identification techniques [34], and molecular fingerprinting techniques based on the random amplification of genome-conserved repetitive regions (AFLPs, RAPDS, and REP fingerprinting) [35-37]. The generation of rapid fingerprints based on the restriction pattern of amplified conserved sequences in polyketide 
synthase or nonribosomal peptide synthetase biosynthetic systems provides additional information about the diversity and the biosynthetic potential of the new isolates [38].

3.3. Cultivation and Extraction. Traditionally the generation of microbial product libraries was based on the empiric cultivation of microbial strains in several nutritional conditions using different liquid and solid formats in varying volumes and by extracting the fermentation broths to generate crude extracts or semipurified fractions containing mixtures of specialized metabolites. The use of a limited number of three to four conditions at once, employing different media compositions, cultivation formats, or incubation periods or temperatures, was generally accepted as being sufficient to produce new, specialized metabolites, without real knowledge of the nutritional requirements and physiology of most of the groups of strains being screened and the key elements involved in regulating their specialized metabolite production. Nowadays, the continuously increasing number of whole-genome sequences of known producers shows that a large fraction of the genome remains silent and that switching on cryptic pathways might trigger the production of novel molecules [3942]. The OSMAC (one strain, many compounds) approach has been proposed as an alternative way of exploring each strain in multiple conditions to better exploit their specialized metabolism and to trigger part of this microbial biosynthetic potential [43]. The use of multiple nutritional conditions has recently been explored by many groups to generate large screening extracts libraries in different formats (tubes, flasks), but miniaturized, parallel fermentation in deep-well plates represented a major breakthrough in the scale and numbers of conditions that can be tested [44]. All major taxonomic groups of actinomycetes and filamentous fungi can be cultivated in a large variety of complex and synthetic liquid media of diverse composition in carbon sources, inorganic or complex nitrogen sources, trace elements, and phosphatecontrolled levels [20]. By testing in parallel a high number of nutritional conditions, minor groups of isolates can be explored and screened for the production of antibiotic activities. Identifying production media that can further promote their microbial biosynthetic potential increases the chances of producing novel molecules and identifying active extracts that can be then pursued on a larger scale in chemical isolation projects $[45,46]$.

The production of specialized bacterial metabolites can be stimulated by using known chemical inducers (e.g., siderophores, rare earths, or metabolism intermediates) [47-50], small, diffusible, bacterial, hormone-like molecules such as the $\gamma$-butyrolactones, and other butenolides [51]. Other elicitors of specialized metabolism include $\mathrm{N}$-acetyl-glucosamine that when added to production media modulates the $\mathrm{N}$ acetyl-glucosamine-responsive protein DasR [52] or generating ribosomal mutations that result in altered ppGpp biosynthesis and catabolite repression that favor biosynthesis [53]. Epigenetic modulation of fungal expression by histone acetylation and methylation has a strong influence on antibiotic production [54], and small-molecule epigenetic inhibitors of histone deacetylase (HDAC) or DNA methyltransferase (DMAT) are used to activate silent, natural product pathways in different fungal species $[55,56]$. Similarly to fungi, HDAC inhibitors such as sodium butyrate or splitomicin have been reported to activate cryptic pathways in Streptomyces coelicolor, and HDAC orthologues have been identified to be broadly distributed in actinomycetes [57], offering new avenues to induce cryptic or poorly expressed specialized metabolites in these taxa and expand the chemical diversity of microbial product libraries.

Whereas the production conditions are key to promoting the biosynthetic potential, microbial product libraries comprise a collection of extracts and are also defined by the type of extraction used in their preparation. Extraction procedures should be designed to ensure the widest diversity of compound polarities in the extracts. These can range from simple whole-broth extraction with solvents of different polarity (from aqueous methanol or acetone miscible with the broth to more nonpolar solvents such as ethyl acetate or methyl-ethyl-ketone, providing cleaner extracts of mid-polarity compounds) to solid-phase extraction with ion exchange resins that directly enrich metabolites from the broth (cross-linked polystyrene Diaion HP20 or XAD resins) $[58,59]$. Orthogonal fractionations that are used to generate prefractionated libraries reduce the complexity of the extracts, enabling screening at higher concentrations and simplifying the following dereplication phase [60].

3.4. Antibacterial Screening Assays. Antibiotic screening strategies of natural products have seen an important evolution in the past few decades, from the low-throughput, early phenotypic assays - used to identify compounds only targeting pathogens without any previous potential mode of action hypothesis-to high-throughput, whole-cell, target-based assays and structured-based design derived from in silico screening $[61,62]$. High-throughput screening of microbial product libraries continues to be commonly based on phenotypic assays that have the advantage of utilizing intact bacteria and ensure that the active compound can penetrate the bacterial membranes and reach their target. Nowadays, these assays offer the possibility of integrating reporter genes to run whole-cell, target-based screens, in liquid- or agarbased format, including single- or two-plate assays, which aim to identify differential activity. The different types of assays targeting classical bacterial functions and essential pathways, including DNA replication, cell wall biosynthesis, and protein biosynthesis, have been extensively described in recent papers $[63,64]$. Among these approaches, one of the breakthroughs is the use of Staphylococcus aureus genes essential for growth to develop a series of screens based on reducing the expression of targets to identify bacterial inhibitors. The induction of antisense RNAs to selectively decrease the production of intracellular gene products has been developed as a primary screening procedure for discovering new antibiotics [65] and was effectively employed to find novel classes of inhibitors with novel modes of action, such as the fatty acid synthesis inhibitors platensimycin and platencin, and a long list of new protein synthesis and protein secretion inhibitors [64]. An effective screening approach has consisted in the use of mechanism-based profiling using the $S$. aureus fitness test-based genome-wide screening for 
upfront empiric evaluation of the antimicrobial activities derived from the screening of microbial product libraries on a wide panel of bacterial pathogens [66]. The S. aureus fitness test consists of a collection of inducible $S$. aureus antisense RNA strains engineered for reduced expression of a single target that corresponds to essential genes for which inducible antisense RNA expression determines a growth phenotype. This assay generates a profile of strain sensitivities specific for the mechanism of action (MOA) of the compound being tested and it has been used to profile and reveal novel activities in crude microbial product extracts [63].

3.5. Chemical Dereplication Process. Given that known molecules continue to be rediscovered in microbial product extracts, all the HTS screening strategies have been accompanied by the implementation of efficient, early LC-MS dereplication platforms to identify known compounds in natural products databases containing known antibiotic compound spectra [67]. For identification of the bioactive compounds in microbial products extracts, bioassay-guided fractionation and further purification of the active molecule from new, large-scale refermentation of the original microbial producer are required. To miniaturize the production conditions in HTS, the desired metabolites need to be reproduced in larger fermentation formats (tubes, flasks, and bioreactors; see the following section on fermentation) later on. After confirming the original hit activity in the new extract, several rounds of chromatographic separations following the biological activity in the enriched fractions ensure that the active component has been enriched. Analysis of the active fractions by LCMS in each round of fractionation permits dereplication of any known components that can be recognized in reference natural product databases and explains the observed activity. Normally, three to four rounds of fractionation are needed to obtain the desired molecule as a pure compound with $>95 \%$ purity $[68,69]$. NMR and LC-MS analytical methods are then applied not only to assess the purity of the compounds but also to generate the dossier of spectra needed to elucidate the structure of the novel compounds [60].

\section{Fermentation Is Often the Only Way to Produce Novel Natural Microbial Products}

Antibiotics are the most important category of bioactive compounds extracted from microorganisms using fermentation. During the discovery process, which is based on biologically guided screening (see the section above), sufficient amounts of active fractions need to be produced by selected microbial strains for the initial biological profiling and to elucidate the chemical structure. During the development and clinical phases, the large-scale production of antibiotics from microbial fermentations is coupled with an intensive effort to improve the strain (see the section below) in order to reduce production volumes and costs and guarantee quality and reproducibility of the drug bulks. Later, when marketing the antibiotic, which is driven by profitability and competitiveness, lower operational costs with concurrently higher yields are required for microbial production [21]. To achieve that goal, manipulating and improving microbial strains and their growing conditions (upstream process) remain the main tools since any purification scheme (downstream) at this stage is hard to improve and change due to the rigorous manufacturing regulations.

For the majority of antibiotics, the only feasible supply process continues to be fermentation, total synthesis being too complicated or too expensive. Table 1 shows that the vast majority of the antibiotic drugs introduced into the market since 2000 are microbial products and are still produced by fermentation. Most natural products are so complex and contain so many centers of asymmetry that they probably will never be produced commercially by chemical synthesis. As an example, total chemical synthesis of the glycopeptide teicoplanin was performed by substantially inventing a new chemistry [70], but it is too expensive and microbial fermentation remains the only way to produce this valuable drug [71, 72]. However, compared to synthetic processes, manufacture by fermentation is more difficult to control; thus, it can lead to the formation of more variable antibiotic products with more complicated and less predictable composition and impurity profiles. This is due to the fact that (a) the purity of the active substances is dependent on the fungal or bacterial strains that produce the antibiotic; (b) the conditions under which strains are processed may vary; (c) the raw materials that are utilized, including the quality of water in which the strains grow, may also vary; and (d) the extraction and purification processes may have limited selectivity [73].

Hence, the crude product obtained by fermentation might not be a single antibiotic substance or entity, but rather a complex mixture of analogues, as is the case with teicoplanin (a complex of five related compounds designated teicoplanins $\mathrm{A}_{2-1}-\mathrm{A}_{2-5}$ characterized by five different linear or branched ten- or eleven-carbon fatty acids) [72], colistin (a multicomponent polypeptide antibiotic, comprised mainly of colistins $\mathrm{A}$ and $\mathrm{B}$ ) [74], and gentamicin (oligosaccharide antibiotic composed of a mixture of three components designated as $\mathrm{C}^{\prime}$, $\mathrm{C}^{\prime} \mathrm{a}$, and C2) [75]. Therefore, it might be difficult to compare apparently identical active ingredients unless they originate from the same manufacturer.

The need to improve the fermentation process (and reduce the cost of a multistep process) is particularly demanding for producing those natural scaffolds that undergo semisynthetic modification, as in the case of the second-generation glycopeptides (dalbavancin: trade name Dalvance, Durata Therapeutics; oritavancin: trade name Orbactiv, The Medicins Company; telavancin: trade name Vibativ, Theravance) recently approved by the Food and Drug Administration (FDA) [76].

4.1. Antibiotic Fermentation Process. Notwithstanding the key role of the fermentation process, not very much has changed since the first submerged fermentation process was developed to meet the demand for penicillins after the Second World War and the processes for producing antibiotics today are very similar to those employed 60 years ago. The fermentation process usually starts with a working cell bank (WCB) inoculated in a flask containing a vegetative medium (in which production does not occur) to allow the strain to grow. After a period that can vary depending on the strain, one or 
TABLE 1: Examples of natural products (NP), semisynthetic modified natural products (SNP), natural product-derived but produced by chemical synthesis (NP-derived), or totally synthetic antibiotics (S) launched since 2000: production method, chemical class, activity against Gram-positive and/or Gram-negative bacteria, lead source, and producing organism.

\begin{tabular}{|c|c|c|c|c|c|c|}
\hline Production & Class & NP-lead source & Lead source & $\begin{array}{c}\text { Antibacterial } \\
\text { spectrum }\end{array}$ & Drug name & Year approved \\
\hline $\begin{array}{l}\text { Chemical } \\
\text { synthesis }\end{array}$ & Oxazolidinone & & S & G+ & Linezolid & 2000 \\
\hline $\begin{array}{l}\text { Fed-batch } \\
\text { fermentation }\end{array}$ & Lipopeptide & $\begin{array}{l}\text { Actinomycete } \\
\text { (Streptomyces } \\
\text { roseosporus) }\end{array}$ & SNP (A21978C) & G+ & Daptomycin & 2003 \\
\hline $\begin{array}{l}\text { Chemical } \\
\text { synthesis }\end{array}$ & Carbapenem & & NP-derived & $\mathrm{G}+/ \mathrm{G}-$ & Doripenem & 2005 \\
\hline $\begin{array}{l}\text { Fed-batch } \\
\text { fermentation }\end{array}$ & Pleuromutilin & $\begin{array}{c}\text { Fungus } \\
\text { (Pleurotus spp.) }\end{array}$ & $\begin{array}{c}\text { SNP } \\
\text { (pleuromutilin) }\end{array}$ & $\mathrm{G}+$ & Retapamulin & 2007 \\
\hline $\begin{array}{l}\text { Fed-batch } \\
\text { fermentation }\end{array}$ & Glycopeptide & $\begin{array}{c}\text { Actinomycete } \\
\text { (Amycolatopsis spp.) }\end{array}$ & SNP (vancomycin) & G+ & Telavancin & 2009 \\
\hline $\begin{array}{l}\text { Fed-batch } \\
\text { fermentation }\end{array}$ & $\beta$-lactam & $\begin{array}{c}\text { Fungus } \\
\text { (Cephalosporium } \\
\text { acremonium) }\end{array}$ & $\begin{array}{c}\text { SNP } \\
\text { (cephalosporin) }\end{array}$ & $\mathrm{G}+/ \mathrm{G}-$ & $\begin{array}{l}\text { Ceftaroline } \\
\text { fosamil }\end{array}$ & 2010 \\
\hline $\begin{array}{l}\text { Fed-batch } \\
\text { fermentation }\end{array}$ & Tiacumicin & $\begin{array}{c}\text { Actinomycete } \\
\text { (Dactylosporangium } \\
\text { aurantiacum) }\end{array}$ & $\mathrm{NP}$ & $\mathrm{G}+$ & Fixadomicin & 2011 \\
\hline $\begin{array}{l}\text { Fed-batch } \\
\text { fermentation }\end{array}$ & Glycopeptide & $\begin{array}{c}\text { Actinomycete } \\
\text { (Nonomuraea sp.) }\end{array}$ & SNP (A40926) & $\mathrm{G}+$ & Dalbavancin & 2014 \\
\hline
\end{tabular}

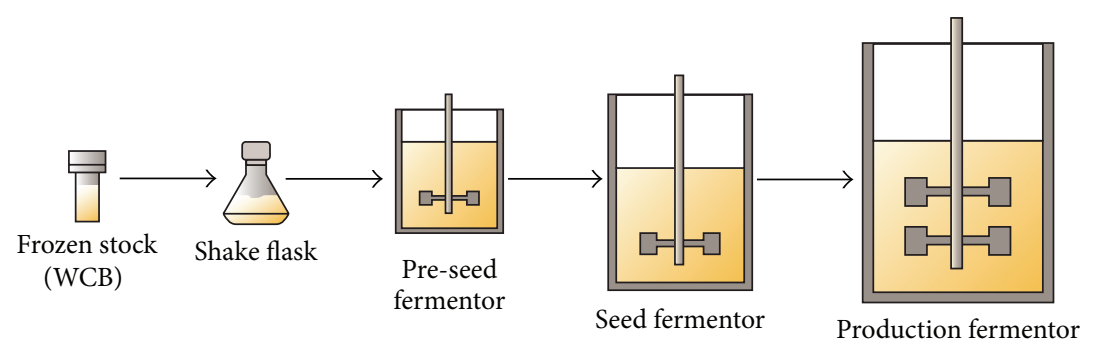

FIGURE 2: Flow diagram for the classical fermentation process: the number of seed steps may vary according to the final scale of the production fermentor.

a series of increasing volume reactors containing vegetative medium are serially inoculated to obtain enough material to start the last-vessel fermentation within the production medium (Figure 2). Submerged fermentations for producing antibacterials are usually performed in stirred tank reactors and are operated in batch or fed-batch mode. In batch reactors all components, except gaseous substrates such as oxygen, $\mathrm{pH}$-controlling substances, and antifoaming agents, are placed in the reactor at the beginning of the fermentation.

Batch processes are simple and robust, but the only way to reach a high cell density is the fed-batch mode, which is more complex but allows the metabolism of the strain to be controlled [77]. In a fed-batch process, one or more nutrients are added in order to control the reaction rate according to its concentration, avoiding catabolite repression (see below) [77]. Most antibiotics are produced with the fedbatch system (e.g., teicoplanin [72], daptomycin [78], tylosin [79], and $\beta$-lactams [80]) (see Table 1). Continuous culture is not common in the pharmaceutical industry because the probability of mutation and contamination is higher. Scaling up the fermentation process usually constitutes the final step in any research and development program for largescale industrial manufacture of fermentation products [81]. Production reactor sizes range from 40 to 100 cubic meters. It is important to understand that the process of scaling up a fermentation system is frequently governed by a number of important engineering considerations and is not simply a matter of increasing culture and vessel volume.

\subsection{Regulation of Antibiotic Synthesis and Medium Composi-} tion. Antibiotics are usually not produced during the phase of rapid growth but rather are synthesized during a subsequent stationary phase. Antibiotic production starts when growth is limited after one key nutrient source is exhausted: carbon, nitrogen, or phosphate. For example, penicillin biosynthesis by Penicillium chrysogenum starts when there is no longer any glucose in the culture medium and the fungus starts consuming lactose, a less readily utilized sugar [82].

The main regulation effect in specialized metabolism is, in fact, carbon catabolite repression, defined as the control 
(inactivation) of specific operons in favor of a primary and efficient utilization of a simple carbon source (commonly, but not always, glucose). The operons/genes/enzymes involved in crucial steps of biosynthesizing specialized metabolites are under catabolite repression. Catabolite repression is strictly linked to growth rate and growth phases since only after easily utilizable substrates have been consumed can the efficient production of specialized metabolites begin. Therefore, regulating metabolite biosynthesis ensures that precursors and metabolic energy are invested in the manufacture of specialized metabolites only under environmental circumstances and at developmental stages where those molecules contribute to the fitness of the organism $[83,84]$.

Glucose represses the production of many antibiotics (e.g., daptomycin [78], clavulanic acid [85], and aminoglycoside antibiotics such as streptomycin, kanamycin, neomycin, and gentamicin), but the molecular mechanism underlying glucose repression has resisted molecular analysis for a long time, although more recently this topic was thoroughly elucidated and widely covered in the literature [49, 84-87]. Readily utilizable nitrogen sources repress enzymes of specialized metabolism during the biosynthesis of cephalosporin [54, 88], cephamycin [89], tylosin [90], and erythromycin [91]. Similarly, free inorganic phosphate depletion from the growth medium is required to trigger production of tetracyclines [92, 93], $\beta$-lactams, and glycopeptides $[93,94]$. Whereas the molecular mechanism for PhoP-mediated phosphate control is partially understood at the molecular level $[93,94]$, the signal sensors and signal transduction cascades involved in regulating metabolism by other stress factors need to be further elucidated [49].

To improve the production of antibiotics, slow-metabolizing carbon, nitrogen, and phosphorous sources are used: complex substrates such as polysaccharides (e.g., starch), oligosaccharides (e.g., lactose), and oils (e.g., soybean oil) are often preferred to glucose, and yeast extract, corn steep liquor, and soybean flour are commonly essential components for supplying nitrogen, phosphorous, vitamins, and trace elements to antibiotic-producing strains. In media containing a mixture of rapidly used carbon, nitrogen, and phosphorous sources and slowly used sources, the former are used first to produce cells and the latter employed once the rapidly assimilated compounds are depleted to sustain the production of specialized metabolites during the stationary phase of growth. Recent examples of how optimization of medium composition contributes to improving the final product concentration, yield, and volumetric productivity have been reported on daptomycin, nisin, cephalosporin C, clavulanic acid, and A40926, the precursor of semisynthetic dalbavancin $[72,78,95-100]$. In the case of daptomycin produced by Streptomyces roseosporus NRRL11379, Ng and coworkers have successfully established a cost-effective medium and feedback-controlling approach by utilizing dextrin as the major carbon source in fed-batch fermentation [78]. For glycopeptide antibiotics such as A40926 and teicoplanin, optimized media and processes have recently been proposed [65, 98100]. The increasing list of specialized metabolism elicitors and chemical inducers, such as siderophores, rare earths, metabolism intermediates, diffusible bacterial hormone-like molecules, and $\mathrm{N}$-acetyl-glucosamine, epigenetic modulators that are being used to activate cryptic or silent gene clusters during the screening processes (see previous paragraph on cultivation and extraction), can be also added to the production media to improve antibiotic production [47-57]. Limits in their use during scaling up of the fermentation process and product development consist in their cost and in the risk of chemical cross-contamination during the purification phase (downstream). Recent molecular studies have provided new insight into the role of catabolite carbon control. They demonstrated a relationship between antibiotic production and morphological development involving $\mathrm{N}$-acetyl-glucosamine, which, when added to production media, modulates the $\mathrm{N}$-acetyl-glucosamine-responsive protein DasR and pleiotropic regulation of both antibiotic synthesis and spore formation [52]. Molecular investigations also elucidated the role of ribosomal/RNA polymerase mutations resulting in altered ppGpp biosynthesis and in stringent response interplaying with catabolite repression $[49,101]$. A thorough understanding of how global regulators (see section below on strain improvement) respond to a variety of nutritional or environmental stress signals, for example, phosphate, carbon, nitrogen starvation, heat shock, $\mathrm{pH}$ stress, and cell wall damage, is currently providing a more rational approach for defining medium and process conditions for antibiotic production $[49,91,93]$.

\section{Strain Improvement in the Postgenomic Era}

With the development and advent of genome sequencing technologies $[102,103]$, it became obvious that most bacterial genomes contain a hidden wealth of clusters responsible for the biosynthesis of potential bioactive compounds [39-41] that await discovery. The main reason for the existence of such a plethora of undiscovered biosynthetic pathways is that many gene clusters are dormant or not expressed in sufficient quantities to be detected under typical fermentation conditions [104-106]. As discussed above, this is related to the existence of tight regulatory networks that precisely orchestrate specialized metabolite production in bacteria and respond to different environmental and intracellular signals $[49,86,107]$. Undoubtedly, a low yield of natural products represents a serious hurdle on the way to commercial production. Therefore, exploring and understanding the interplay between antibiotic production, regulatory networks, environmental and intracellular signals will provide us with keys to understanding specialized metabolite overproduction.

Nowadays, numerous strategies for improving strains have been and continue to be developed. Classical approaches for strain improvement were based on recursive rounds of mutagenesis and further selection [108, 109]. Despite the drawbacks (unwanted mutations and being time consuming and laborious), this strategy was successful and widely used for rapidly increasing the production yield of antibioticproducing microbes. Most of the industrial overproducers currently in use were developed in this way [110, 111]. However, with the development of molecular biology, biotechnology, bioinformatics, sequencing technologies, and synthetic biology, new strategies have come to the scene and provide the opportunity for rational strain improvement (Figure 3). 


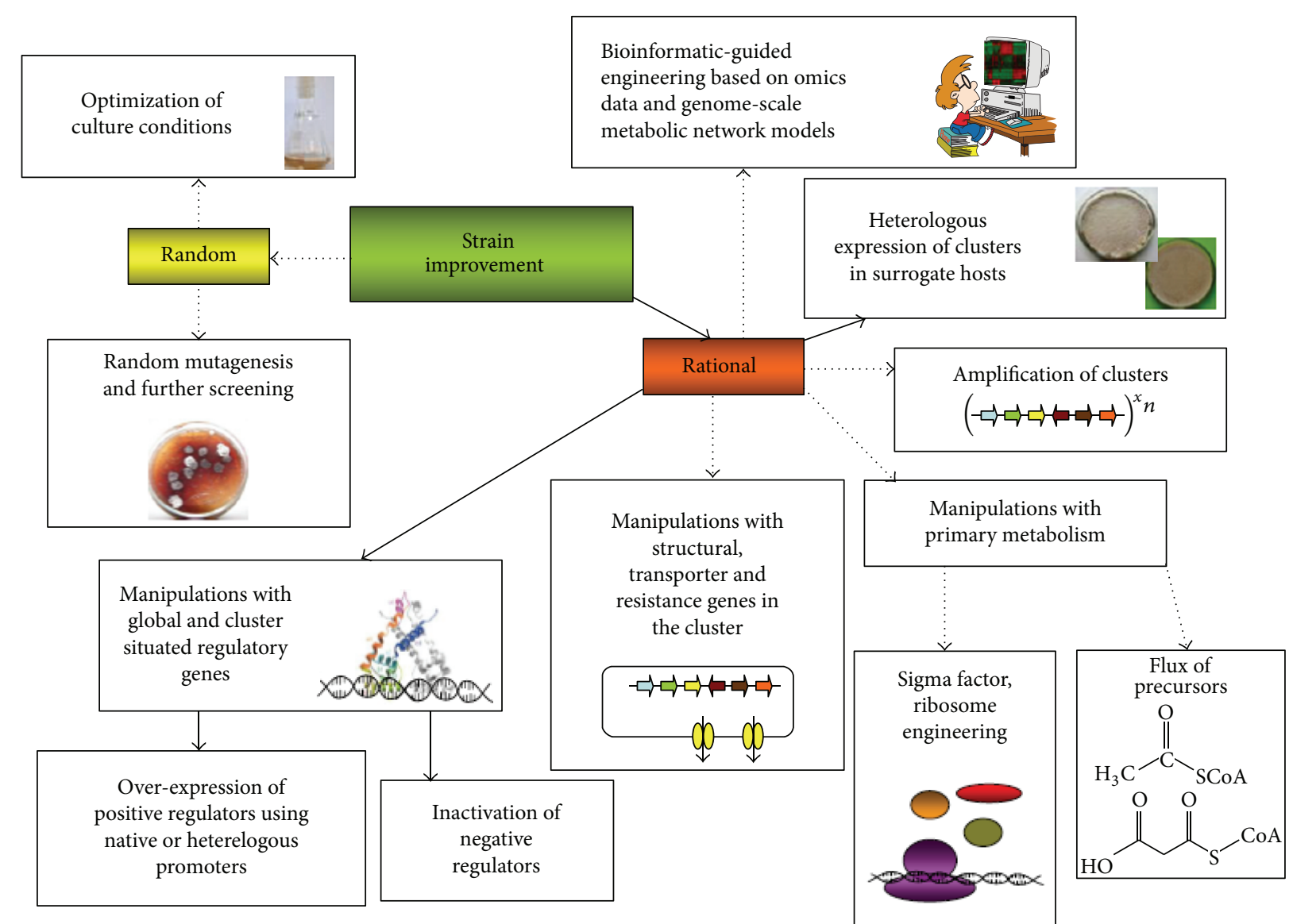

FIGURE 3: Approaches used for improving secondary metabolite production in actinobacteria. Solid arrows indicate strategies described in this review; dash-dotted arrows denote other strategies that are used.

Overall, all of these relatively new approaches are based on spatial, temporal, and quantitative regulation of gene expression at the transcriptional or translational level, or both, thereby enabling production of higher amounts of specialized metabolites by overcoming bottlenecks, optimizing expression of genes, and redirecting the flux of precursors. Therefore, titer can be elevated by overexpressing positive regulators or deleting repressors [94, 104, 112, 113]; amplifying gene clusters [114]; redirecting the flux of primary metabolites and precursors [104-115]; overexpressing structural genes that constitute bottlenecks on the way to metabolite production [116, 117]; manipulating resistance genes and transporters responsible for the flux of antibiotic [118-120]; ribosomal engineering $[101,105]$; and so forth. Substituting native promoters in a cluster with well-defined, strong promoters, either constitutive or inducible, gives an opportunity to bypass existing regulatory machinery of the host strain and improve production $[121,122]$. In some cases appreciable yields of metabolites can be obtained by expressing gene clusters in surrogate hosts which are easy to manipulate (Streptomyces lividans, Streptomyces albus) or which are industrial strains (Streptomyces avermitilis) or which are genetically engineered, versatile hosts with reduced genomes (S. avermitilis SUKA, Streptomyces coelicolor M1154) [123-125]. In the following section of the review, only some examples of using regulatory genes, promoters, and heterologous hosts for rational strain improvement will be reported. Many superb and in-depth reviews have been published recently that describe different approaches for metabolic engineering of actinobacteria [104, $112,113,126,127]$. We refer the readers to them for a further comprehensive introduction to these topics.

5.1. Regulatory Genes as Basic Keys to Metabolite Overproduction. Genes involved in the production of antibiotics are located together on a chromosome or plasmid and form biosynthetic clusters. Such clusters usually contain structural, resistance, transporter, and regulatory genes. Therefore, regulatory genes that are associated with cluster and control biosynthesis of certain compound are named pathwayspecific or cluster-situated regulators (CSR). They form the lowest level in the hierarchically organized regulatory network of antibiotic production in bacteria [49]. Since production of specialized metabolites is tightly connected to morphological differentiation and depends on a plethora of environmental conditions, expression of CSRs hinges on a variety of other pleiotropic, higher-level regulators that sense and transmit signals to them. In turn, CSRs, which are usually final checkpoints, transfer these signals to structural genes and switch biosynthesis of natural products on and off $[49,86]$. However, like for every rule, there are exceptions 
in the structure of biosynthetic gene clusters. Elucidation of the genetic organization of numerous biosynthetic pathways revealed that there are some which lack CSRs $[128,129]$. These findings indicate that the cluster-situated layer of regulation is not mandatory and is absent in some clusters. In such clusters, the expression of structural genes is controlled by ubiquitous regulatory genes that occupy higher levels in the regulatory web $[128,129]$.

According to how specialized metabolite production is influenced, all regulators can be conventionally classified into two groups: positive regulators, which activate, and negative regulators, which repress the biosynthesis of natural products. With the aim of enhancing the titer, both pleiotropic and CSRs, native and heterologous ones, are used. CSRs usually give an opportunity to manipulate one biosynthetic pathway, whereas global regulators might affect production of several specialized metabolites and/or morphological differentiation. Therefore, the effect of a pleiotropic regulatory gene very often depends on its position in the hierarchically organized regulatory network and in some cases might be unpredictable.

\subsection{Manipulations with Positive Cluster-Situated Regulatory} Genes. Overexpression of positive, pathway-specific regulators mainly enhances the transcription of structural genes responsible for the production of certain metabolites and therefore is a commonly used, single-step strategy for improving antibiotic yield. Herein, we will describe examples demonstrating the effectiveness of this approach for rational strain improvement.

Streptomyces globisporus 1912 is used to produce the angucycline antibiotic landomycin $\mathrm{E}(\mathrm{LaE})$. The landomycin biosynthetic gene cluster contains only one regulator gene, IndI, whose product is highly similar to the OmpR-PhoB subfamily of proteins. By inactivating it, antibiotic production was prevented in the I2-1 mutant, which confirms the role of LndI as an activator of LaE biosynthesis. Complementation of the I2-1 mutant with three additional copies of $\ln d I$ gene resulted in 15 -fold increase in LaE production in comparison to the wild-type strain 1912 [130], demonstrating the effectiveness of such an approach for improving the strain.

Simocyclinone D8 is an aminocoumarin compound that is produced by Streptomyces antibioticus Tü6040. simReg1, which belongs to the OmpR-PhoB subfamily of regulators, is one of three regulatory genes in the simocyclinone biosynthetic gene cluster. Its inactivation abolished antibiotic production, while overexpression of simReg1 in an integrative pSET152-derived plasmid increased the simocyclinone titer 2.5-fold [131].

Other examples are as follows: (a) the C-1027 titer in S. globisporus was improved 5-fold after overexpressing the sgcR1 gene, coding for a StrR-like protein [132]; (b) amplifying the claR gene encoding the LysR family protein in multicopy plasmids resulted in a threefold increase in clavulanic acid biosynthesis and in a sixfold increase in alanylclavam production [133]; (c) inserting a single copy of pimM, a LuxR type regulator, into the $S$. natalensis wild-type strain elevated pimaricin production 2.4-fold [134]; (d) overexpressing $f d m R 1$, the encoding pathway-specific activator of the SARP family, led to a 5.6-fold increased production of fredericamycin A in S. griseus [135]; (e) amplifying the tcp28 or tcp29 genes, which encode StrR and LuxR family regulators, respectively, in the Actinoplanes teichomyceticus wild-type strain boosted teicoplanin production 1.5-3-fold [136, 137].

\subsection{Manipulations with Negative Cluster-Situated Regulatory} Genes. An effective and promising alternative method to overexpressing cluster-situated activators to boost antibiotic production is to inactivate pathway-specific repressors. This is exemplified by the disruption of the lipReg3 gene coding for the MarR-type regulator that controls lipomycin export in S. aureofaciens Tüll7, which led to a 4-fold improvement in lipomycin production in comparison to the wild-type strain [138].

Other examples that have proven the effectiveness of this strategy are as follows: (a) inactivation of the jadR2 gene, coding a "pseudo" $\gamma$-butyrolactones receptor, in S. venezuelae generated the mutant that produces jadomycin without stress treatments (toxic concentration of ethanol, etc.) [139, 140]; (b) inactivation of another deduced $\gamma$-butyrolactone receptor coding gene tylP led to a 1.5 -fold improvement in tylosin production in S. fradiae [141]; (c) deletion of the ptmR1, encoding GntR type repressor, in S. platensis MA7327 resulted in, on average, 100-fold overproduction of platensimycin and platencin compared to the wild-type strain [142]; and (d) inactivation of the TetR type regulator alpW in $S$. ambofaciens triggered constitutive production of kinamycin, a compound with antibacterial activity [143]. Thus, inactivation of repressor coding genes is useful not only for elevating antibiotic production, but, in some cases, for wakening silent gene clusters.

5.4. Manipulations with Pleiotropic Regulatory Genes. Successful application of omnipresent positive pleiotropic regulators to improve the titer of compounds whose biosynthetic gene clusters contain CSRs, or which are free of them, has also been shown. In most cases, a positive effect of their overexpression is due to the activation of cluster-situated regulatory gene expression or direct activation of the expression of structural genes in the cluster. For instance, overexpression of the pleiotropic regulator afsRsv in S. venezuelae, S. peucetius, and S. lividans TK24 led to a 4.85-, 8-, and 1.5-fold increase in pikromycin, doxorubicin, and actinorhodin production, respectively, relative to the wild type [144]. In the case of S. venezuelae, the increase in pikromycin production was caused by enhanced expression of the pathway-specific regulator gene pikD and the ketosynthase gene [144]. By introducing additional copies of the afsR or afs $S$ genes into $S$. coelicolor, actinorhodin production could also be increased [145].

Streptomyces ghanaensis is a producer of phosphoglycolipid antibiotic moenomycin A [146]. The moenomycin biosynthetic gene cluster does not contain CSRs; therefore, different pleiotropic regulators were used to improve the moenomycin titer. Overexpression of the adpAgh gene, a pleiotropic regulator of antibiotic production and morphological development, led to a 2.5 -fold improvement in moenomycin production in S. ghanaensis compared to the wild-type strain [129]. Introduction of the second copy of bldAgh, a leucyl 
tRNA coding gene, into the wild-type strain S. ghanaensis led to a 1.6-fold increase in moenomycin production [129]. Overexpression of the relA, a ppGpp synthetase gene from $S$. coelicolor, led to a 2-fold improvement in moenomycin production in S. ghanaensis relative to the wild type [147].

Similarly, inactivation of negative pleiotropic regulators in $S$. ghanaensis increased moenomycin production. The gene $a b s B$ codes for the RNAseIII endoribonuclease involved in global regulation of morphological differentiation and antibiotic production in S. coelicolor [148]. By deleting it, moenomycin production was improved 2.7-fold compared with the parental strain [129]. Inactivation of another global regulator gene, $w b l A(g h)$, encoding a homologue of the WhiB-family of proteins, produced a 2.3-fold increase in moenomycin biosynthesis in S. ghanaensis [149].

Disruption of the (p)ppGpp synthetase gene, relA, in $S$. clavuligerus boosted clavulanic acid production 3- to 4-fold and that of cephamycin C increased about 2.5-fold [150], confirming that there might be a pleiotropic effect of global regulator amplification or inactivation.

5.5. Promoters as Bio-Bricks for Titer Improvement. Another common metabolic engineering approach to induce or enhance the expression of silent or poorly expressed pathways is based on replacing native promoters in a cluster with welldefined, strong promoters, decoupling the metabolic pathway from the existing cellular regulatory networks. Examples described below clearly prove the effectiveness of the combination of two metabolic engineering strategies: amplification of positive regulators and their expression under the control of heterologous promoters of various strengths.

For this purpose different natural or synthetic constitutive or inducible promoters may be used $[137,151]$. One of the most widely employed promoters in streptomycetes is the erythromycin resistance gene ermEp from Saccharopolyspora erythraea or its upregulated variant ermE ${ }^{*}$ [152]. For example, simultaneous overexpression of the $d n r N, d n r I$, and $a f_{s} R$ regulatory genes under the control of ermEp ${ }^{*}$ in $S$. peucetius led to a 4.3-fold increase in doxorubicin production [153]. Another prominent example of the use of this promoter is the improvement in tylosin production in S. fradiae. Biosynthesis of tylosin is orchestrated by the complicated interplay of five regulators [154]. To bypass existing regulatory networkpositive regulators, $t y l S$ or $t y l R$ was placed under the control of the ermEp ${ }^{*}$ and overexpressed in the S. fradiae wildtype strain. This boosted tylosin production 3.8- and 5.0-fold, respectively [154]. Production of teicoplanin in the nonstreptomycetes actinomycete $A$. teichomyceticus was improved 2.8fold and 10-fold by overexpressing the StrR-type regulator tcp28 under the control of the promoter of the SARP regulator gene actII-ORF4 and apramycin gene resistance promoter $(\operatorname{aac}(3) I V p)$, respectively, which appeared to be stronger in this strain than the widely used ermEp [136, 137]. This reflects the necessity to test the activity of heterologous promoters in a particular strain since their activity might differ in various species. Therefore, the repertoire of available promoters should be extended.
5.6. Heterologous Expression of Clusters as a Way to Overproduction. With the advent of genome sequencing and metagenomics, a plethora of clusters coding for putative biologically active compounds which previously eluded discovery because of silencing or low product yield have become and continue to become available. In addition, there are growing numbers of actinobacteria that are difficult to culture and to manipulate genetically but which produce or might produce interesting chemical compounds. The reasons outlined above drove the development of a new approach in metabolic engineering for developing surrogate high-producing hosts for the heterologous expression of gene clusters. There are a number of potential surrogate hosts. Some of them derive from well-studied Streptomyces strains such as S. lividans, S. coelicolor, or S. albus; others are obtained from industrial strains or are genetically engineered, versatile hosts with reduced genomes. However, the main aim of this approach is still relevant and aims to build an ideal and universal surrogate host that will be easy to genetically manipulate, is fast growing and devoid of competitive sinks of carbon and nitrogen and antibiotic activity, and will be suitable for overproduction of different specialized metabolites.

To improve moenomycin production, several Streptomyces strains were used as heterologous hosts, namely, $S$. coelicolor M145, M512 ( $\triangle$ actII-ORF4, $\Delta$ redD), S. lividans TK24, 1326, S. albus J1074, S. venezuelae ATCC10712, and S. thermospinosisporus NRRL_B24318. The highest moenomycin titer was found in $S$. albus strains, the lowest in $S$. coelicolor [147]. These data show a high variation between different hosts. Worthy of note is that the yield of antibiotic in $S$. albus was on average 4 times higher than in the native producer S. ghanaensis [147].

There are several genetically engineered heterologous hosts that were obtained by controlled minimization of genomes. For example, S. coelicolor M1154 was constructed by deleting four gene clusters (actinorhodin, prodiginine, calcium-dependent antibiotic, and cryptic polyketide) and subsequently introducing point mutations in the $r p o B$ and $r p s L$ genes that enhance specialized metabolite production [125]. Expression of the gene clusters for chloramphenicol or congocidine in this strain led to a 40- and 30-fold increase in production, respectively, in comparison to the $S$. coelicolor M145 strain. Another surrogate host was developed on the basis of the industrial strain S. avermitilis [124]. A region of more than $1.4 \mathrm{Mb}$ that contains nonessential genes and gene clusters was deleted stepwise from the chromosome of S. avermitilis. Expression of cephamycin C, streptomycin, and pladienolide biosynthetic gene clusters was tested in the obtained strains. Production level of streptomycin in SUKA5 strain was approximately 3 times higher than in the native producer. Biosynthesis of cephamycin C was also greatly improved. However, the biosynthesis was switched on only in the presence of the activator CcaR. Substitution of the native promoter of the $c c a R$ gene with the alternative $r p s J$ promoter led to an additional increase in cephamycin $C$ production [124], underscoring the urgency and need to use the approaches outlined above to further improve antibiotic 
production in genetically engineered heterologous hosts. The production of pladienolide in S. avermitilis engineered strains was also higher than in the S. avermitilis wild type [124].

Attempts to use well-studied, fast-growing, easy-tomanipulate, versatile, and widely used heterologous host such as Escherichia coli for the expression of actinobacterial gene clusters have also been made. This is exemplified by the production of the important antibacterial drug rifamycin. The starter unit for the RifA megasynthases is 3-amino-5hydroxybenzoic acid (AHBA). The latter requires seven genes for biosynthesis, which are present in the rifamycin gene cluster [155]. First of all, the ability to synthesize the AHBA intermediate was reconstituted in E. coli BAP1. Afterwards, RifA was expressed in the AHBA-producing strain in the form of two bimodular proteins. As a result, the rifamycin intermediate P8_1-OG was synthesized at a quantity of $2.5 \mathrm{mg} / \mathrm{L}$ [155]. Other attempts to express erythromycin and oxytetracycline gene clusters in E. coli have also been described [156, 157]. Despite several successful tries, numerous attempts to overexpress Streptomyces gene clusters in E. coli failed. Currently, the main obstacles on the way to the desired metabolites in E. coli are high GC content of genes, absence of starter and extender units necessary for production, and differences in regulatory networks that generate an inability to effectively transcribe heterologous pathways. However, despite these drawbacks and taking into account number of advantages, E. coli continues to be an appealing host for heterologous expression of actinobacterial gene clusters.

\section{Conclusions}

Despite the diverse classes of antibacterials that have been discovered from microbial natural product screening, there is an urgent medical need for novel molecules endowed with novel mechanisms of action to counteract emerging and multiresistant Gram-positive and Gram-negative pathogens. The microbial diversity at the origin of these novel drugs will continue to guarantee those unprecedented chemical characteristics and biological properties that did not emerge from screening libraries of synthetic compounds. Classical biological activity-based screening for novel antibacterials also relies on previous knowledge of the ecology and genome information of microbial isolates to assess their potential to produce different compounds under different cultivation conditions. Fermentation media and other parameters are being changed, taking into consideration knowledgebased use of different elicitors and tailored carbon, nitrogen, and phosphorous sources. The dramatic advances made in exploring and understanding the interplay between antibiotic production, regulatory networks, and environmental and intracellular signals are now providing us with keys to discover and overproduce new antibiotics. Currently, a wide range of genetic engineering approaches offer a large choice of tools for rational strain and fermentation improvement that might speed up the discovery and development of new, effective drugs. Combination of a growing body of knowledge in modern technologies, such as whole-genome sequencing, transcription, and metabolite profiling, offers the opportunity to make bioinformatics-based predictions of possible ways for discovering and improving specialized metabolites. Undoubtedly, further developments in functional genomics and other analytic techniques that lead to the discovery of many new signal transduction pathways and new transcription factors will reveal new, attractive targets for strain improvement approaches in the near future. In addition, approaches used in metabolic engineering continue to provide an excellent basis not only for creating overproducers, but to ensure further exploration and exploitation of the hidden part of microbial wealth. The main goal today is to develop a suite of technologies that could be used to induce the production of cryptic metabolic genes and identify previously unreported molecules, with sufficient yields to overcome one of the major problems of this century: the lack of new antibiotics.

\section{Conflict of Interests}

The authors declare that there is no conflict of interests regarding the publication of this paper.

\section{Authors' Contribution}

All the authors equally contributed to the review.

\section{References}

[1] H. H. Lee, M. N. Molla, C. R. Cantor, and J. J. Collins, "Bacterial charity work leads to population-wide resistance," Nature, vol. 467, no. 7311, pp. 82-85, 2010.

[2] Infectious Diseases Society of America, "The $10 \times$ '20 Initiative: pursuing a global commitment to develop 10 new antibacterial drugs by 2020," Clinical Infectious Diseases, vol. 50, no. 8, pp. 1081-1083, 2010.

[3] R. M. Klevens, J. R. Edwards, C. L. Richards Jr. et al., "Estimating health care-associated infections and deaths in U.S. hospitals, 2002," Public Health Reports, vol. 122, pp. 160-166, 2007.

[4] National Institute of Allergy and Infectious Diseases (NIAID), The Problem of Antimicrobial Resistance, 2006, https://www.idph .state.ia.us/adper/common/pdf/abx/tab9_niaid_resistance.pdf.

[5] European Centre for Disease Prevention and Control (ECDC), Annual Epidemiological Report on Communicable Diseases in Europe, European Centre for Disease Prevention and Control, Stockholm, Sweden, 2008.

[6] L. B. Rice, "Federal funding for the study of antimicrobial resistance in nosocomial pathogens: No ESKAPE," Journal of Infectious Diseases, vol. 197, no. 8, pp. 1079-1081, 2008.

[7] L. R. Peterson, "Bad bugs, no drugs: no ESCAPE revisited," Clinical Infectious Diseases, vol. 49, no. 6, pp. 992-993, 2009.

[8] H. Lode, "Management of serious nosocomial bacterial infections: do current therapeutic options meet the need?" Clinical Microbiology and Infection, vol. 11, no. 10, pp. 778-787, 2005.

[9] J. M. Rybak, K. E. Barber, and M. J. Rybak, "Current and prospective treatments for multidrug-resistant gram-positive infections," Expert Opinion on Pharmacotherapy, vol. 14, no. 14, pp. 1919-1932, 2013.

[10] N. Woodford and D. M. Livermore, "Infections caused by Gram-positive bacteria: a review of the global challenge," Journal of Infection, vol. 59, supplement 1, pp. S4-S16, 2009. 
[11] S. E. Cosgrove, Y. Qi, K. S. Kaye, S. Harbarth, A. W. Karchmer, and Y. Carmeli, "The impact of methicillin resistance in Staphylococcus aureus bacteremia on patient outcomes: mortality, length of stay, and hospital charges," Infection Control and Hospital Epidemiology, vol. 26, no. 2, pp. 166-174, 2005.

[12] J. N. Pendleton, S. P. Gorman, and B. F. Gilmore, "Clinical relevance of the ESKAPE pathogens," Expert Review of AntiInfective Therapy, vol. 11, no. 3, pp. 297-308, 2013.

[13] E. M. Santayana, S. A. Grim, W. M. Janda, J. E. Layden, T. A. Lee, and N. M. Clark, "Risk factors and outcomes associated with vancomycin-resistant Enterococcus infections with reduced susceptibilities to linezolid," Diagnostic Microbiology and Infectious Disease, vol. 74, no. 1, pp. 39-42, 2012.

[14] L. L. Maragakis, "Recognition and prevention of multidrugresistant Gram-negative bacteria in the intensive care unit," Critical Care Medicine, vol. 38, supplement 8, pp. S345-S351, 2010.

[15] C. G. Giske, D. L. Monnet, O. Cars, and Y. Carmeli, "Clinical and economic impact of common multidrug-resistant gramnegative bacilli," Antimicrobial Agents and Chemotherapy, vol. 52, no. 3, pp. 813-821, 2008.

[16] L. B. Rice, "Challenges in identifying new antimicrobial agents effective for treating infections with Acinetobacter baumannii and Pseudomonas aeruginosa," Clinical Infectious Diseases, vol. 43, supplement 2, pp. S100-S105, 2006.

[17] H. Kallel, M. Bahloul, L. Hergafi et al., "Colistin as a salvage therapy for nosocomial infections caused by multidrug-resistant bacteria in the ICU," International Journal of Antimicrobial Agents, vol. 28, no. 4, pp. 366-369, 2006.

[18] M. E. Falagas, I. A. Bliziotis, S. K. Kasiakou, G. Samonis, P. Athanassopoulou, and A. Michalopoulos, "Outcome of infections due to pandrug-resistant (PDR) Gram-negative bacteria," BMC Infectious Diseases, vol. 5, article 24, 2005.

[19] M. E. Falagas, P. I. Rafailidis, D. K. Matthaiou, S. Virtzili, D. Nikita, and A. Michalopoulos, "Pandrug-resistant Klebsiella pneumoniae, Pseudomonas aeruginosa and Acinetobacter baumannii infections: characteristics and outcome in a series of 28 patients," International Journal of Antimicrobial Agents, vol. 32, no. 5, pp. 450-454, 2008.

[20] F. Marinelli, "From microbial products to novel drugs that target a multitude of disease indications," Methods in Enzymology, vol. 458, pp. 29-58, 2009.

[21] F. Marinelli and G. L. Marcone, "Small molecules-microbial secondary metabolites," in Comprehensive Biotechnology, M. Moo-Young, Ed., Elsevier BV, Dordrecht, The Netherlands, 2nd edition, 2011.

[22] M. G. Watve, R. Tickoo, M. M. Jog, and B. D. Bhole, "How many antibiotics are produced by the genus Streptomyces?" Archives of Microbiology, vol. 176, no. 5, pp. 386-390, 2001.

[23] H. Bredholt, E. Fjærvik, G. Johnsen, and S. B. Zotchev, "Actinomycetes from sediments in the Trondheim fjord, Norway: diversity and biological activity," Marine Drugs, vol. 6, no. 1, pp. 12-24, 2008.

[24] I. González, A. Ayuso-Sacido, A. Anderson, and O. Genilloud, "Actinomycetes isolated from lichens: evaluation of their diversity and detection of biosynthetic gene sequences," FEMS Microbiology Ecology, vol. 54, no. 3, pp. 401-415, 2005.

[25] S. J. Higginbotham, A. E. Arnold, A. Ibañez, C. Spadafora, P. D. Coley, and T. A. Kursar, "Bioactivity of fungal endophytes as a function of endophyte taxonomy and the taxonomy of their host plants," PLoS ONE, vol. 8, no. 9, Article ID e73192, 2013.
[26] J. E. Janso and G. T. Carter, "Biosynthetic potential of phylogenetically unique endophytic actinomycetes from tropical plants," Applied and Environmental Microbiology, vol. 76, no. 13, pp. 4377-4386, 2010.

[27] M. Poulsen, D.-C. Oh, J. Clardy, and C. R. Currie, "Chemical analyses of wasp-associated Streptomyces bacteria reveal a prolific potential for natural products discovery," PLOS ONE, vol. 6, no. 2, Article ID e16763, 2011.

[28] K. E. R. Davis, S. J. Joseph, and P. H. Janssen, "Effects of growth medium, inoculum size, and incubation time on culturability and isolation of soil bacteria," Applied and Environmental Microbiology, vol. 71, no. 2, pp. 826-834, 2005.

[29] P. H. Janssen, P. S. Yates, B. E. Grinton, P. M. Taylor, and M. Sait, "Improved culturability of soil bacteria and isolation in pure culture of novel members of the divisions Acidobacteria, Actinobacteria, Proteobacteria, and Verrucomicrobia," Applied and Environmental Microbiology, vol. 68, no. 5, pp. 2391-2396, 2002.

[30] D. Nichols, N. Cahoon, E. M. Trakhtenberg et al., "Use of ichip for high-throughput in situ cultivation of 'uncultivable' microbial species," Applied and Environmental Microbiology, vol. 76, no. 8, pp. 2445-2450, 2010.

[31] S.-I. Suzuki, "Establishment and use of gellan gum media for selective isolation and distribution survey of specific rare actinomycetes," Actinomycetologica, vol. 15, no. 2, pp. 55-60, 2001.

[32] V. Govindasamy, C. M. M. Franco, and V. V. S. R. Gupta, "Endophytic actinobacteria: diversity and ecology," in Advances in Endophytic Research, V. C. Verma and A. C. Gange, Eds., pp. 27-59, Springer, New Delhi, India, 2014.

[33] P. A. C. Braga, A. Tata, V. G. dos Santos et al., "Bacterial identification: from the agar plate to the mass spectrometer," RSC Advances, vol. 3, no. 4, pp. 994-1008, 2013.

[34] P. Schumann and T. Maier, "MALDI-TOF mass spectrometry applied to classification and identification of bacteria," Methods in Microbiology, vol. 41, pp. 275-306, 2014.

[35] B. Lanoot, M. Vancanneyt, A. van Schoor, Z. Liu, and J. Swings, "Reclassification of Streptomyces nigrifaciens as a later synonym of Streptomyces flavovirens; Streptomyces citreofluorescens, Streptomyces chrysomallus subsp. chrysomallus and Streptomyces fluorescens as later synonyms of Streptomyces anulatus; Streptomyces chibaensis as a later synonym of Streptomyces corchorusii; Streptomyces flaviscleroticus as a later synonym of Streptomyces minutiscleroticus; and Streptomyces lipmanii, Streptomyces griseus subsp. alpha, Streptomyces griseus subsp. cretosus and Streptomyces willmorei as later synonyms of Streptomyces microflavus," International Journal of Systematic and Evolutionary Microbiology, vol. 55, no. 2, pp. 729-731, 2005.

[36] J. Versalovic, M. Schneider, F. J. de Bruijn, and J. R. Lupski, "Genomic fingerprinting of bacteria using repetitive sequencebased polymerase chain reaction," Methods in Molecular and Cellular Biology, vol. 5, no. 1, pp. 25-40, 1994.

[37] P. Vos, R. Hogers, M. Bleeker et al., "AFLP: a new technique for DNA fingerprinting," Nucleic Acids Research, vol. 23, no. 21, pp. 4407-4414, 1995.

[38] A. Ayuso, D. Clark, I. González, O. Salazar, A. Anderson, and O. Genilloud, "A novel actinomycete strain de-replication approach based on the diversity of polyketide synthase and nonribosomal peptide synthetase biosynthetic pathways," Applied Microbiology and Biotechnology, vol. 67, no. 6, pp. 795-806, 2005. 
[39] S. D. Bentley, K. F. Chater, A.-M. Cerdeño-Tárraga et al., "Complete genome sequence of the model actinomycete Streptomyces coelicolor A3(2)," Nature, vol. 417, no. 6885, pp. 141-147, 2002.

[40] H. Ikeda, J. Ishikawa, A. Hanamoto et al., "Complete genome sequence and comparative analysis of the industrial microorganism Streptomyces avermitilis," Nature Biotechnology, vol. 21, no. 5, pp. 526-531, 2003.

[41] D. W. Udwary, L. Zeigler, R. N. Asolkar et al., "Genome sequencing reveals complex secondary metabolome in the marine actinomycete Salinispora tropica," Proceedings of the National Academy of Sciences of the United States of America, vol. 104, no. 25, pp. 10376-10381, 2007.

[42] J. F. Sanchez, A. D. Somoza, N. P. Keller, and C. C. C. Wang, "Advances in Aspergillus secondary metabolite research in the post-genomic era," Natural Product Reports, vol. 29, no. 3, pp. 351-371, 2012.

[43] H. B. Bode, B. Bethe, R. Höfs, and A. Zeeck, "Big effects from small changes: possible ways to explore nature's chemical diversity," ChemBioChem, vol. 3, no. 7, pp. 619-627, 2002.

[44] W. A. Duetz, "Microtiter plates as mini-bioreactors: miniaturization of fermentation methods," Trends in Microbiology, vol. 15, no. 10, pp. 469-475, 2007.

[45] G. F. Bills, J. Martín, J. Collado et al., "Measuring the distribution and diversity of antibiosis and secondary metabolites in the filamentous fungi," Society of Industrial Microbiology News, vol. 59, pp. 133-147, 2009.

[46] O. Genilloud, I. González, O. Salazar, J. Martín, J. R. Tormo, and F. Vicente, "Current approaches to exploit actinomycetes as a source of novel natural products," Journal of Industrial Microbiology and Biotechnology, vol. 38, no. 3, pp. 375-389, 2011.

[47] K. Kawai, G. Wang, S. Okamoto, and K. Ochi, "The rare earth, scandium, causes antibiotic overproduction in Streptomyces spp," FEMS Microbiology Letters, vol. 274, no. 2, pp. 311-315, 2007.

[48] X. Wang, K. A. Shaaban, S. I. Elshahawi et al., "Frenolicins C-G, pyranonaphthoquinones from Streptomyces sp. RM-4-15," Journal of Natural Products, vol. 76, no. 8, pp. 1441-1447, 2013.

[49] G. P. van Wezel and K. J. McDowall, "The regulation of the secondary metabolism of Streptomyces: new links and experimental advances," Natural Product Reports, vol. 28, no. 7, pp. 1311-1333, 2011.

[50] K. Yamanaka, H. Oikawa, H.-O. Ogawa et al., "Desferrioxamine E produced by Streptomyces griseus stimulates growth and development of Streptomyces tanashiensis," Microbiology, vol. 151, no. 9, pp. 2899-2905, 2005.

[51] C. Corre, L. Song, S. O’Rourke, K. F. Chater, and G. L. Challis, "2-Alkyl-4-hydroxymethylfuran-3-carboxylic acids, antibiotic production inducers discovered by Streptomyces coelicolor genome mining," Proceedings of the National Academy of Sciences of the United States of America, vol. 105, no. 45, pp. 1751017515, 2008.

[52] S. Rigali, F. Titgemeyer, S. Barends et al., "Feast or famine: the global regulator DasR links nutrient stress to antibiotic production by Streptomyces," EMBO Reports, vol. 9, no. 7, pp. 670-675, 2008.

[53] T. Hosaka, M. Ohnishi-Kameyama, H. Muramatsu et al., "Antibacterial discovery in actinomycetes strains with mutations in RNA polymerase or ribosomal protein S12," Nature Biotechnology, vol. 27, no. 5, pp. 462-464, 2009.

[54] A. A. Brakhage and V. Schroeckh, "Fungal secondary metabolites-strategies to activate silent gene clusters," Fungal Genetics and Biology, vol. 48, no. 1, pp. 15-22, 2011.
[55] M. de la Cruz, J. Martín, V. González-Menéndez et al., “Chemical and physical modulation of antibiotic activity in Emericella species," Chemistry \& Biodiversity, vol. 9, no. 6, pp. 1095-1113, 2012.

[56] R. B. Williams, J. C. Henrikson, A. R. Hoover, A. E. Lee, and R. $\mathrm{H}$. Cichewicz, "Epigenetic remodeling of the fungal secondary metabolome," Organic and Biomolecular Chemistry, vol. 6, no. 11, pp. 1895-1997, 2008.

[57] J. M. Moore, E. Bradshaw, R. F. Seipke, M. I. Hutchings, and M. McArthur, "Use and discovery of chemical elicitors that stimulate biosynthetic gene clusters in Streptomyces bacteria," Methods in Enzymology, vol. 517, pp. 367-385, 2012.

[58] M. S. Butler, F. Fontaine, and M. A. Cooper, "Natural product libraries: assembly, maintenance, and screening," Planta Medica, vol. 80, no. 14, pp. 1161-1170, 2014.

[59] V. González-Menéndez, F. Asensio, C. Moreno et al., "Assessing the effects of adsorptive polymeric resin additions on fungal secondary metabolite chemical diversity," Mycology, vol. 5, no. 3, pp. 179-191, 2014.

[60] D. Camp, R. A. Davis, E. A. Evans-Illidge, and R. J. Quinn, "Guiding principles for natural product drug discovery," Future Medicinal Chemistry, vol. 4, no. 9, pp. 1067-1084, 2012.

[61] D. J. Payne, M. N. Gwynn, D. J. Holmes, and D. L. Pompliano, "Drugs for bad bugs: confronting the challenges of antibacterial discovery," Nature Reviews Drug Discovery, vol. 6, no. 1, pp. 2940, 2007.

[62] L. L. Silver, "Rational approaches to antibacterial discovery: pre-genomic directed and phenotypic screening," in Antibiotic Discovery and Development, T. J. Dougherty and M. J. Pucci, Eds., Springer Science, New York, NY, USA, 2012.

[63] O. Genilloud and F. Vicente, "Strategies to discover novel antimicrobials to cope with emerging medical needs," in Antimicrobials: New and Old Molecules in the Fight Against Multi-Resistant Bacteria, F. Marinelli and O. Genilloud, Eds., chapter 17, pp. 327-360, Springer, Berlin, Germany, 2014.

[64] S. B. Singh, K. Young, and L. Miesel, "Screening strategies for discovery of antibacterial natural products," Expert Review of Anti-Infective Therapy, vol. 9, no. 8, pp. 589-613, 2011.

[65] R. A. Forsyth, R. J. Haselbeck, K. L. Ohlsen et al., "A genomewide strategy for the identification of essential genes in Staphylococcus aureus," Molecular Microbiology, vol. 43, no. 6, pp. 13871400, 2002.

[66] R. G. K. Donald, S. Skwish, R. A. Forsyth et al., "A Staphylococcus aureus fitness test platform for mechanism-based profiling of antibacterial compounds," Chemistry and Biology, vol. 16, no. 8, pp. 826-836, 2009.

[67] F. E. Koehn and G. T. Carter, "The evolving role of natural products in drug discovery," Nature Reviews Drug Discovery, vol. 4, no. 3, pp. 206-220, 2005.

[68] F. Bucar, A. Wube, and M. Schmid, "Natural product isolationhow to get from biological material to pure compounds," Natural Product Reports, vol. 30, no. 4, pp. 525-545, 2013.

[69] F. E. Koehn, "High impact technologies for natural products screening," in Natural Compounds as Drugs, F. Petersen and R. Amstutz, Eds., vol. 1, Birkhäuser, Basel, Switzerland, 2008.

[70] D. L. Boger, S. H. Kim, Y. Mori et al., "First and second generation total synthesis of the teicoplanin aglycon," Journal of the American Chemical Society, vol. 123, no. 9, pp. 1862-1871, 2001.

[71] G. L. Marcone and F. Marinelli, "Glycopeptides: an old but upto-date successful antibiotic class," in Antimicrobials-New and Old Molecules in the Fight Against Multi-Resistant Bacteria, F. 
Marinelli and O. Genilloud, Eds., Springer, Berlin, Germany, 2014.

[72] C. Taurino, L. Frattini, G. L. Marcone, L. Gastaldo, and F. Marinelli, "Actinoplanes teichomyceticus ATCC 31121 as a cell factory for producing teicoplanin," Microbial Cell Factories, vol. 10, article 82, 2011.

[73] A. J. Brink, G. A. Richards, G. Colombo, F. Bortolotti, P. Colombo, and F. Jehl, "Multicomponent antibiotic substances produced by fermentation: implications for regulatory authorities, critically ill patients and generics," International Journal of Antimicrobial Agents, vol. 43, no. 1, pp. 1-6, 2014.

[74] J. Li, R. L. Nation, J. D. Turnidge et al., "Colistin: the reemerging antibiotic for multidrug-resistant Gram-negative bacterial infections," The Lancet Infectious Diseases, vol. 6, no. 9, pp. 589-601, 2006.

[75] C. G. Kumar, M. Himabindu, and A. Jetty, "Microbial biosynthesis and applications of gentamicin: a critical appraisal," Critical Reviews in Biotechnology, vol. 28, no. 3, pp. 173-212, 2008.

[76] E. Binda, F. Marinelli, and G. L. Marcone, "Old and New Glycopeptide Antibiotics: Action and Resistance," Antibiotics, vol. 3, pp. 572-594, 2014.

[77] J. C. Teodoro, A. Baptista-Neto, I. L. Cruz-Hernández, C. O. Hokka, and A. C. Badino, "Influence of feeding conditions on clavulanic acid production in fed-batch cultivation with medium containing glycerol," Applied Microbiology and Biotechnology, vol. 72, no. 3, pp. 450-455, 2006.

[78] I.-S. Ng, C. Ye, Z. Zhang, Y. Lu, and K. Jing, "Daptomycin antibiotic production processes in fed-batch fermentation by Streptomyces roseosporus NRRL11379 with precursor effect and medium optimization," Bioprocess and Biosystems Engineering, vol. 37, no. 3, pp. 415-423, 2014.

[79] P. P. Gray and K. Vu-Trong, "Production of the macrolide antibiotic Tylosin in cyclic fed-batch culture," Biotechnology and Bioengineering, vol. 29, no. 1, pp. 33-40, 1987.

[80] R. P. Elander, "Industrial production of $\beta$-lactam antibiotics," Applied Microbiology and Biotechnology, vol. 61, no. 5-6, pp. 385-392, 2003.

[81] G. Wang, J. Chu, H. Noorman et al., "Prelude to rational scale-up of penicillin production: a scale-down study," Applied Microbiology and Biotechnology, vol. 98, no. 6, pp. 2359-2369, 2014.

[82] S. S. Weber, R. A. L. Bovenberg, and A. J. M. Driessen, "Biosynthetic concepts for the production of $\beta$-lactam antibiotics in Penicillium chrysogenum," Biotechnology Journal, vol. 7, no. 2, pp. 225-236, 2012.

[83] S. Sanchez and A. L. Demain, "Metabolic regulation of fermentation processes," Enzyme and Microbial Technology, vol. 31, no. 7, pp. 895-906, 2002.

[84] S. Sánchez, A. Chávez, A. Forero et al., "Carbon source regulation of antibiotic production," Journal of Antibiotics, vol. 63, no. 8, pp. 442-459, 2010.

[85] K.-C. Chen, Y.-H. Lin, C.-M. Tsai, C.-H. Hsieh, and J.-Y. Houng, "Optimization of glycerol feeding for clavulanic acid production by Streptomyces clavuligerus with glycerol feeding," Biotechnology Letters, vol. 24, no. 6, pp. 455-458, 2002.

[86] G. Liu, K. F. Chater, G. Chandra, G. Niu, and H. Tan, "Molecular regulation of antibiotic biosynthesis in Streptomyces," Microbiology and Molecular Biology Reviews, vol. 77, no. 1, pp. 112-143, 2013.

[87] H. Zhu, S. K. Sandiford, and G. P. van Wezel, "Triggers and cues that activate antibiotic production by actinomycetes," Journal of
Industrial Microbiology \& Biotechnology, vol. 41, no. 2, pp. 371386, 2014.

[88] J. Li, Y. Pan, and G. Liu, "Disruption of the nitrogen regulatory gene AcareA in Acremonium chrysogenum leads to reduction of cephalosporin production and repression of nitrogen metabolism," Fungal Genetics and Biology, vol. 61, pp. 69-79, 2013.

[89] A. L. Leitão, F. J. Enguita, J. F. Martín, and J. F. Santos Oliveira, "Effect of exogenous lysine on the expression of early cephamycin $\mathrm{C}$ biosynthetic genes and antibiotic production in Nocardia lactamdurans MA4213," Applied Microbiology and Biotechnology, vol. 56, no. 5-6, pp. 670-675, 2001.

[90] D. Choi, O. Y. Choi, H.-J. Shin, D.-O. Chung, and D.-Y. Shin, "Tylosin production by Streptomyces fradiae using raw cornmeal in airlift bioreactor," Journal of Microbiology and Biotechnology, vol. 17, no. 7, pp. 1071-1078, 2007.

[91] L.-L. Yao, C.-H. Liao, G. Huang et al., "GlnR-mediated regulation of nitrogen metabolism in the actinomycete Saccharopolyspora erythraea," Applied Microbiology and Biotechnology, vol. 98, no. 18, pp. 7935-7948, 2014.

[92] J. F. Martín, "Phosphate control of the biosynthesis of antibiotics and other secondary metabolites is mediated by the PhoR-PhoP system: an unfinished story," Journal of Bacteriology, vol. 186, no. 16, pp. 5197-5201, 2004.

[93] J. F. Martín, F. Santos-Beneit, A. Rodríguez-García et al., “Transcriptomic studies of phosphate control of primary and secondary metabolism in Streptomyces coelicolor," Applied Microbiology and Biotechnology, vol. 95, no. 1, pp. 61-75, 2012.

[94] J.-F. Martín and P. Liras, "Engineering of regulatory cascades and networks controlling antibiotic biosynthesis in Streptomyces," Current Opinion in Microbiology, vol. 13, no. 3, pp. $263-$ 273, 2010.

[95] X.-X. Zhou, Y.-J. Pan, Y.-B. Wang, and W.-F. Li, “Optimization of medium composition for nisin fermentation with response surface methodology," Journal of Food Science, vol. 73, no. 6, pp. M245-M249, 2008.

[96] W. A. Lotfy, "The utilization of beet molasses as a novel carbon source for cephalosporin C production by Acremonium chrysogenum: optimization of process parameters through statistical experimental designs," Bioresource Technology, vol. 98, no. 18, pp. 3491-3498, 2007.

[97] Y. H. Wanga, B. Yangb, J. Renb, M. L. Donga, D. Lianga, and A. L. Xua, "Optimization of medium composition for the production of clavulanic acid by Streptomyces clavuligerus," Process Biochemistry, vol. 40, no. 3-4, pp. 1161-1166, 2005.

[98] N. Gunnarsson, P. Bruheim, and J. Nielsen, "Production of the glycopeptide antibiotic A40926 by Nonomuraea sp. ATCC 39727: influence of medium composition in batch fermentation," Journal of Industrial Microbiology and Biotechnology, vol. 30, no. 3, pp. 150-156, 2003.

[99] F. Beltrametti, S. Jovetic, M. Feroggio, L. Gastaldo, E. Selva, and F. Marinelli, "Valine influence production and complex composition of glycopeptide antibiotic A40926 in fermentations of Nonomuraea sp. ATCC 39727,' Journal of Antibiotics, vol. 57, no. 1, pp. 37-44, 2004.

[100] S. Jovetic, M. Feroggio, F. Marinelli, and G. Lancini, "Factors influencing cell fatty acid composition and A40926 antibiotic complex production in Nonomuraea sp. ATCC 39727," Journal of Industrial Microbiology and Biotechnology, vol. 35, no. 10, pp. 1131-1138, 2008.

[101] K. Ochi, S. Okamoto, Y. Tozawa et al., "Ribosome engineering and secondary metabolite production," Advances in Applied Microbiology, vol. 56, pp. 155-184, 2004. 
[102] C. S. Pareek, R. Smoczynski, and A. Tretyn, "Sequencing technologies and genome sequencing," Journal of Applied Genetics, vol. 52, no. 4, pp. 413-435, 2011.

[103] E. Shapiro, T. Biezuner, and S. Linnarsson, "Single-cell sequencing-based technologies will revolutionize whole-organism science," Nature Reviews Genetics, vol. 14, no. 9, pp. 618-630, 2013.

[104] R. H. Baltz, "Strain improvement in actinomycetes in the postgenomic era," Journal of Industrial Microbiology and Biotechnology, vol. 38, no. 6, pp. 657-666, 2011.

[105] K. Ochi and T. Hosaka, "New strategies for drug discovery: activation of silent or weakly expressed microbial gene clusters," Applied Microbiology and Biotechnology, vol. 97, no. 1, pp. 87-98, 2013.

[106] K. Ochi, Y. Tanaka, and S. Tojo, "Activating the expression of bacterial cryptic genes by rpoB mutations in RNA polymerase or by rare earth elements," Journal of Industrial Microbiology and Biotechnology, vol. 41, no. 2, pp. 403-414, 2014.

[107] J. F. Martín, A. Sola-Landa, F. Santos-Beneit, L. T. FernándezMartínez, C. Prieto, and A. Rodríguez-García, "Cross-talk of global nutritional regulators in the control of primary and secondary metabolism in Streptomyces," Microbial Biotechnology, vol. 4, no. 2, pp. 165-174, 2011.

[108] H. Hu and K. Ochi, "Novel approach for improving the productivity of antibiotic-producing strains by inducing combined resistant mutations," Applied and Environmental Microbiology, vol. 67, no. 4, pp. 1885-1892, 2001.

[109] J. L. Adrio and A. L. Demain, "Genetic improvement of processes yielding microbial products," FEMS Microbiology Reviews, vol. 30, no. 2, pp. 187-214, 2006.

[110] N. Tamehiro, T. Hosaka, J. Xu, H. Hu, N. Otake, and K. Ochi, "Innovative approach for improvement of an antibioticoverproducing industrial strain of Streptomyces albus," Applied and Environmental Microbiology, vol. 69, no. 11, pp. 6412-6417, 2003.

[111] M. H. Medema, M. T. Alam, R. Breitling, and E. Takano, "The future of industrial antibiotic production: from random mutagenesis to synthetic biology," Bioengineered Bugs, vol. 2, no. 4, pp. 230-233, 2011

[112] C. Olano, F. Lombó, C. Méndez, and J. A. Salas, "Improving production of bioactive secondary metabolites in actinomycetes by metabolic engineering," Metabolic Engineering, vol. 10, no. 5, pp. 281-292, 2008.

[113] Y. Chen, M. J. Smanski, and B. Shen, "Improvement of secondary metabolite production in Streptomyces by manipulating pathway regulation," Applied Microbiology and Biotechnology, vol. 86, no. 1, pp. 19-25, 2010.

[114] K. Yanai, T. Murakami, and M. Bibb, "Amplification of the entire kanamycin biosynthetic gene cluster during empirical strain improvement of Streptomyces kanamyceticus," Proceedings of the National Academy of Sciences of the United States of America, vol. 103, no. 25, pp. 9661-9666, 2006.

[115] W. Wohlleben, Y. Mast, G. Muth, M. Röttgen, E. Stegmann, and T. Weber, "Synthetic Biology of secondary metabolite biosynthesis in actinomycetes: engineering precursor supply as a way to optimize antibiotic production," FEBS Letters, vol. 586, no. 15, pp. 2171-2176, 2012.

[116] J. Nielsen, "Metabolic engineering," Applied Microbiology and Biotechnology, vol. 55, pp. 263-283, 2001.

[117] J. Thykaer, J. Nielsen, W. Wohlleben et al., "Increased glycopeptide production after overexpression of shikimate pathway genes being part of the balhimycin biosynthetic gene cluster," Metabolic Engineering, vol. 12, no. 5, pp. 455-461, 2010.
[118] G. L. Marcone, E. Binda, L. Carrano, M. Bibb, and F. Marinelli, "Relationship between glycopeptide production and resistance in the actinomycete Nonomuraea sp. ATCC 39727," Antimicrobial Agents and Chemotherapy, vol. 58, no. 9, pp. 5191-5201, 2014.

[119] N. Menéndez, A. F. Braña, J. A. Salas, and C. Méndez, "Involvement of a chromomycin ABC transporter system in secretion of a deacetylated precursor during chromomycin biosynthesis," Microbiology, vol. 153, no. 9, pp. 3061-3070, 2007.

[120] S. Malla, N. P. Niraula, K. Liou, and J. K. Sohng, "Self-resistance mechanism in Streptomyces peucetius: overexpression of $d r r A$, $d r r B$ and $d r r C$ for doxorubicin enhancement," Microbiological Research, vol. 165, no. 4, pp. 259-267, 2010.

[121] L. Horbal, V. Fedorenko, and A. Luzhetskyy, "Novel and tightly regulated resorcinol and cumate-inducible expression systems for Streptomyces and other actinobacteria," Applied Microbiology and Biotechnology, vol. 98, no. 20, pp. 8641-8655, 2014.

[122] Y. Rebets, E. Brötz, B. Tokovenko, and A. Luzhetskyy, "Actinomycetes biosynthetic potential: how to bridge in silico and in vivo?" Journal of Industrial Microbiology and Biotechnology, vol. 41, no. 2, pp. 387-402, 2014.

[123] R. H. Baltz, "Streptomyces and Saccharopolyspora hosts for heterologous expression of secondary metabolite gene clusters," Journal of Industrial Microbiology and Biotechnology, vol. 37, no. 8, pp. 759-772, 2010.

[124] M. Komatsu, T. Uchiyama, S. Omura, D. E. Cane, and H. Ikeda, "Genome-minimized Streptomyces host for the heterologous expression of secondary metabolism," Proceedings of the National Academy of Sciences of the United States of America, vol. 107, no. 6, pp. 2646-2651, 2010.

[125] J. P. Gomez-Escribano and M. J. Bibb, "Engineering Streptomyces coelicolor for heterologous expression of secondary metabolite gene clusters," Microbial Biotechnology, vol. 4, no. 2, pp. 207-215, 2011.

[126] A. K. Chaudhary, D. Dhakal, and J. K. Sohng, "An insight into the "-Omics" based engineering of streptomycetes for secondary metabolite overproduction," BioMed Research International, vol. 2013, Article ID 968518, 15 pages, 2013.

[127] K.-S. Hwang, H. U. Kim, P. Charusanti, B. Ø. Palsson, and S. Y. Lee, "Systems biology and biotechnology of Streptomyces species for the production of secondary metabolites," Biotechnology Advances, vol. 32, no. 2, pp. 255-268, 2014.

[128] C. Chng, A. M. Lum, J. A. Vroom, and C. M. Kao, "A key developmental regulator controls the synthesis of the antibiotic erythromycin in Saccharopolyspora erythraea," Proceedings of the National Academy of Sciences of the United States of America, vol. 105, no. 32, pp. 11346-11351, 2008.

[129] R. Makitrynskyy, B. Ostash, O. Tsypik et al., "Pleiotropic regulatory genes $b l d A, a d p A$ and $a b s B$ are implicated in production of phosphoglycolipid antibiotic moenomycin," Open biology, vol. 3, no. 10, Article ID 130121, 2013.

[130] Y. Rebets, B. Ostash, A. Luzhetskyy et al., "Production of landomycins in Streptomyces globisporus 1912 and S. cyanogenus S136 is regulated by genes encoding putative transcriptional activators," FEMS Microbiology Letters, vol. 222, no. 1, pp. 149153, 2003.

[131] L. Horbal, Y. Rebets, M. Rabyk et al., "SimReg1 is a master switch for biosynthesis and export of simocyclinone D8 and its precursors," AMB Express, vol. 2, article 1, 2012.

[132] Y. Chen, M. Yin, G. P. Horsman, S. Huang, and B. Shen, "Manipulation of pathway regulation in Streptomyces globisporus for 
overproduction of the enediyne antitumor antibiotic C-1027," Journal of Antibiotics, vol. 63, no. 8, pp. 482-485, 2010.

[133] R. Pérez-Redondo, A. Rodríguez-García, J. F. Martín, and P. Liras, "The claR gene of Streptomyces clavuligerus, encoding a LysR-type regulatory protein controlling clavulanic acid biosynthesis, is linked to the clavulanate-9-aldehyde reductase (car) gene," Gene, vol. 211, no. 2, pp. 311-321, 1998.

[134] N. Antón, J. Santos-Aberturas, M. V. Mendes, S. M. Guerra, J. F. Martín, and J. F. Aparicio, "PimM, a PAS domain positive regulator of pimaricin biosynthesis in Streptomyces natalensis," Microbiology, vol. 153, no. 9, pp. 3174-3183, 2007.

[135] Y. Chen, E. Wendt-Pienkowski, and B. Shen, "Identification and utility of FdmR1 as a Streptomyces antibiotic regulatory protein activator for fredericamycin production in Streptomyces griseus ATCC 49344 and heterologous hosts," Journal of Bacteriology, vol. 190, no. 16, pp. 5587-5596, 2008.

[136] L. Horbal, A. Kobylyanskyy, O. Yushchuk et al., "Evaluation of heterologous promoters for genetic analysis of Actinoplanes teichomyceticus-producer of teicoplanin, drug of last defense," Journal of Biotechnology, vol. 168, no. 4, pp. 367-372, 2013.

[137] L. Horbal, A. Kobylyanskyy, A. W. Truman et al., "The pathway-specific regulatory genes, tei15 ${ }^{*}$ and teil6 ${ }^{*}$, are the master switches of teicoplanin production in Actinoplanes teichomyceticus," Applied Microbiology and Biotechnology, vol. 98, no. 22, pp. 9295-9309, 2014.

[138] L. Horbal, Y. Rebets, M. Rabyk et al., "Characterization and analysis of the regulatory network involved in control of lipomycin biosynthesis in Streptomyces aureofaciens Tü117," Applied Microbiology and Biotechnology, vol. 85, no. 4, pp. 10691079, 2010.

[139] K. Yang, L. Han, and L. C. Vining, "Regulation of jadomycin B production in Streptomyces venezuelae ISP5230: involvement of a repressor gene, jadR 2 ," Journal of Bacteriology, vol. 177, no. 21, pp. 6111-6117, 1995.

[140] G. Xu, J. Wang, L. Wang et al., “Pseudo' $\gamma$-butyrolactone receptors respond to antibiotic signals to coordinate antibiotic biosynthesis," Journal of Biological Chemistry, vol. 285, no. 35, pp. 27440-27448, 2010.

[141] G. Stratigopoulos, A. R. Gandecha, and E. Cundliffe, "Regulation of tylosin production and morphological differentiation in Streptomyces fradiae by TylP, a deduced gamma-butyrolactone receptor," Molecular Microbiology, vol. 45, no. 3, pp. 735-744, 2002.

[142] M. J. Smanski, R. M. Peterson, S. R. Rajski, and B. Shen, "Engineered Streptomyces platensis strains that overproduce antibiotics platensimycin and platencin," Antimicrobial Agents and Chemotherapy, vol. 53, no. 4, pp. 1299-1304, 2009.

[143] R. Bunet, L. Song, M. V. Mendes et al., "Characterization and manipulation of the pathway-specific late regulator AlpW reveals Streptomyces ambofaciens as a new producer of kinamycins," Journal of Bacteriology, vol. 193, no. 5, pp. 1142-1153, 2011.

[144] S. Maharjan, T.-J. Oh, H. C. Lee, and J. K. Sohng, "Identification and functional characterization of an $a f s R$ homolog regulatory gene from Streptomyces venezuelae ATCC 15439," Journal of Microbiology and Biotechnology, vol. 19, no. 2, pp. 121-127, 2009.

[145] B. Floriano and M. Bibb, " $a f s R$ is a pleiotropic but conditionally required regulatory gene for antibiotic production in Streptomyces coelicolor A3(2)," Molecular Microbiology, vol. 21, no. 2, pp. 385-396, 1996.
[146] B. Ostash and S. Walker, "Moenomycin family antibiotics: chemical synthesis, biosynthesis, and biological activity," Natural Product Reports, vol. 27, no. 11, pp. 1594-1617, 2010.

[147] R. Makitrynskyy, Y. Rebets, B. Ostash et al., "Genetic factors that influence moenomycin production in Streptomycetes," Journal of Industrial Microbiology and Biotechnology, vol. 37, no. 6, pp. 559-566, 2010.

[148] S. A. Chang, P. Bralley, and G. H. Jones, "The absB gene encodes a double strand-specific endoribonuclease that cleaves the readthrough transcript of the rpsO-pnp operon in Streptomyces coelicolor," Journal of Biological Chemistry, vol. 280, no. 39, pp. 33213-33219, 2005.

[149] M. Rabyk, B. Ostash, Y. Rebets, S. Walker, and V. Fedorenko, "Streptomyces ghanaensis pleiotropic regulatory gene $w b l A_{g h}$ influences morphogenesis and moenomycin production," Biotechnology Letters, vol. 33, no. 12, pp. 2481-2486, 2011.

[150] J. P. Gomez-Escribano, J. F. Martín, A. Hesketh, M. J. Bibb, and P. Liras, "Streptomyces clavuligerusrelA-null mutants overproduce clavulanic acid and cephamycin C: negative regulation of secondary metabolism by (p)ppGpp," Microbiology, vol. 154, no. 3, pp. 744-755, 2008.

[151] T. Siegl, B. Tokovenko, M. Myronovskyi, and A. Luzhetskyy, "Design, construction and characterisation of a synthetic promoter library for fine-tuned gene expression in actinomycetes," Metabolic Engineering, vol. 19, pp. 98-106, 2013.

[152] M. J. Bibb, G. R. Janssen, and J. M. Ward, "Cloning and analysis of the promoter region of the erythromycin resistance gene (ermE) of Streptomyces erythraeus," Gene, vol. 38, no. 1-3, pp. 215-226, 1985.

[153] S. Malla, N. P. Niraula, K. Liou, and J. K. Sohng, "Improvement in doxorubicin productivity by overexpression of regulatory genes in Streptomyces peucetius," Research in Microbiology, vol. 161, no. 2, pp. 109-117, 2010.

[154] N. Bate, A. R. Butler, A. R. Gandecha, and E. Cundliffe, "Multiple regulatory genes in the tylosin biosynthetic cluster of Streptomyces fradiae," Chemistry and Biology, vol. 6, no. 9, pp. 617-624, 1999.

[155] K. Watanabe, M. A. Rude, C. T. Walsh, and C. Khosla, "Engineered biosynthesis of an ansamycin polyketide precursor in Escherichia coli," Proceedings of the National Academy of Sciences of the United States of America, vol. 100, no. 17, pp. 9774-9778, 2003.

[156] D. C. Stevens, K. R. Conway, N. Pearce, L. R. VillegasPeñaranda, A. G. Garza, and C. N. Boddy, "Alternative sigma factor over-expression enables heterologous expression of a Type II polyketide biosynthetic pathway in Escherichia coli," PLoS ONE, vol. 8, no. 5, Article ID e64858, 2013.

[157] X. Gao, P. Wang, and Y. Tang, "Engineered polyketide biosynthesis and biocatalysis in Escherichia coli," Applied Microbiology and Biotechnology, vol. 88, no. 6, pp. 1233-1242, 2010. 

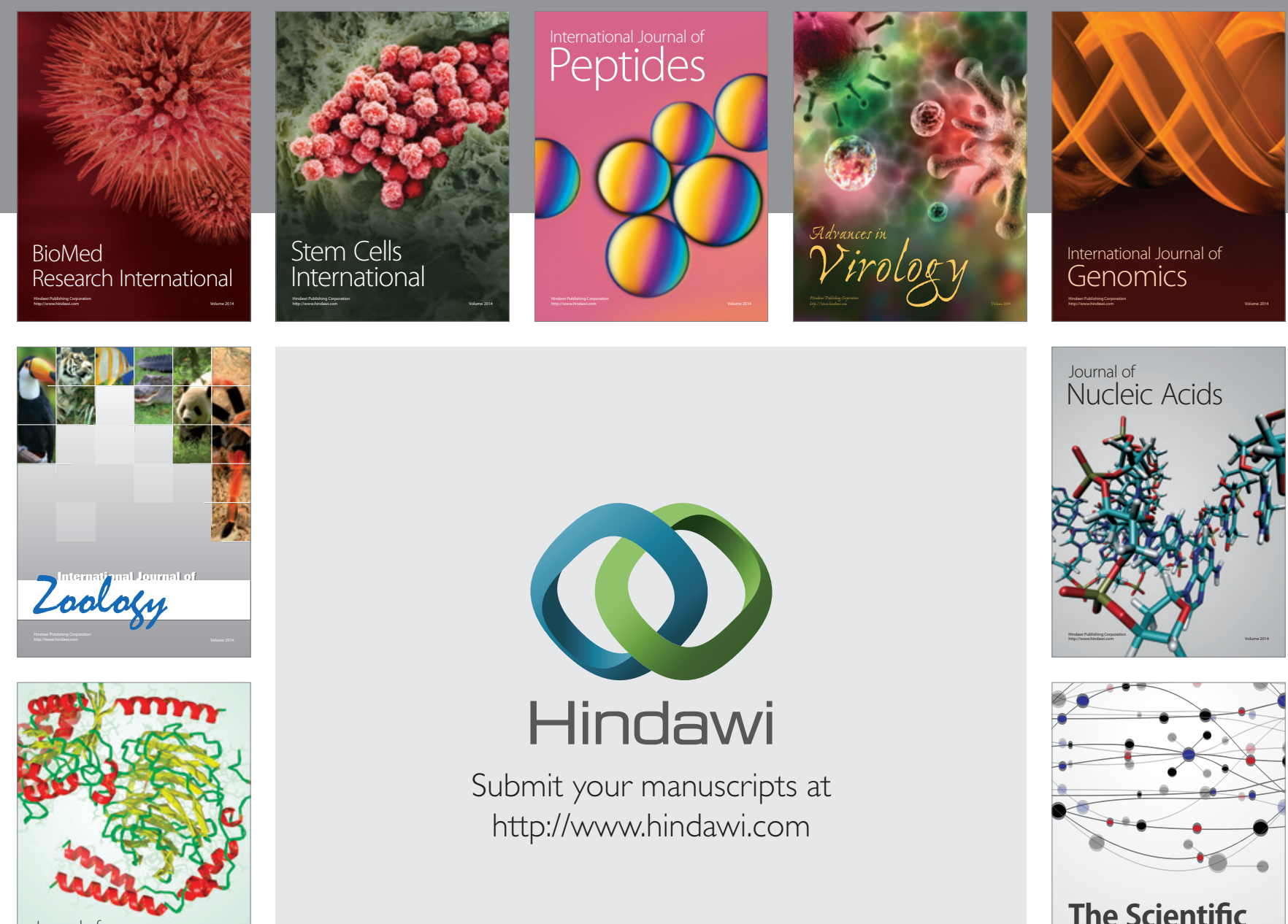

Submit your manuscripts at

http://www.hindawi.com

Journal of
Signal Transduction
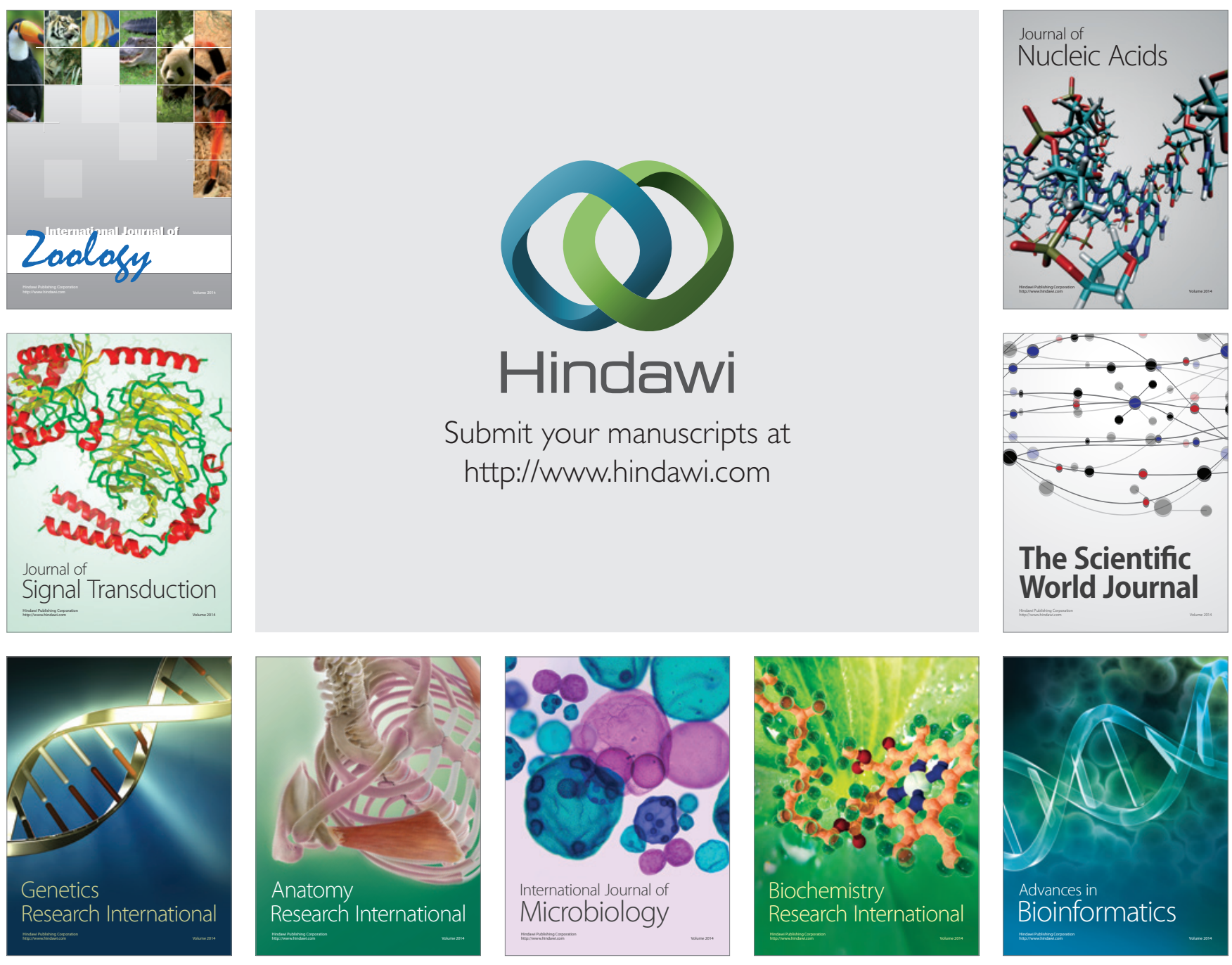

The Scientific World Journal
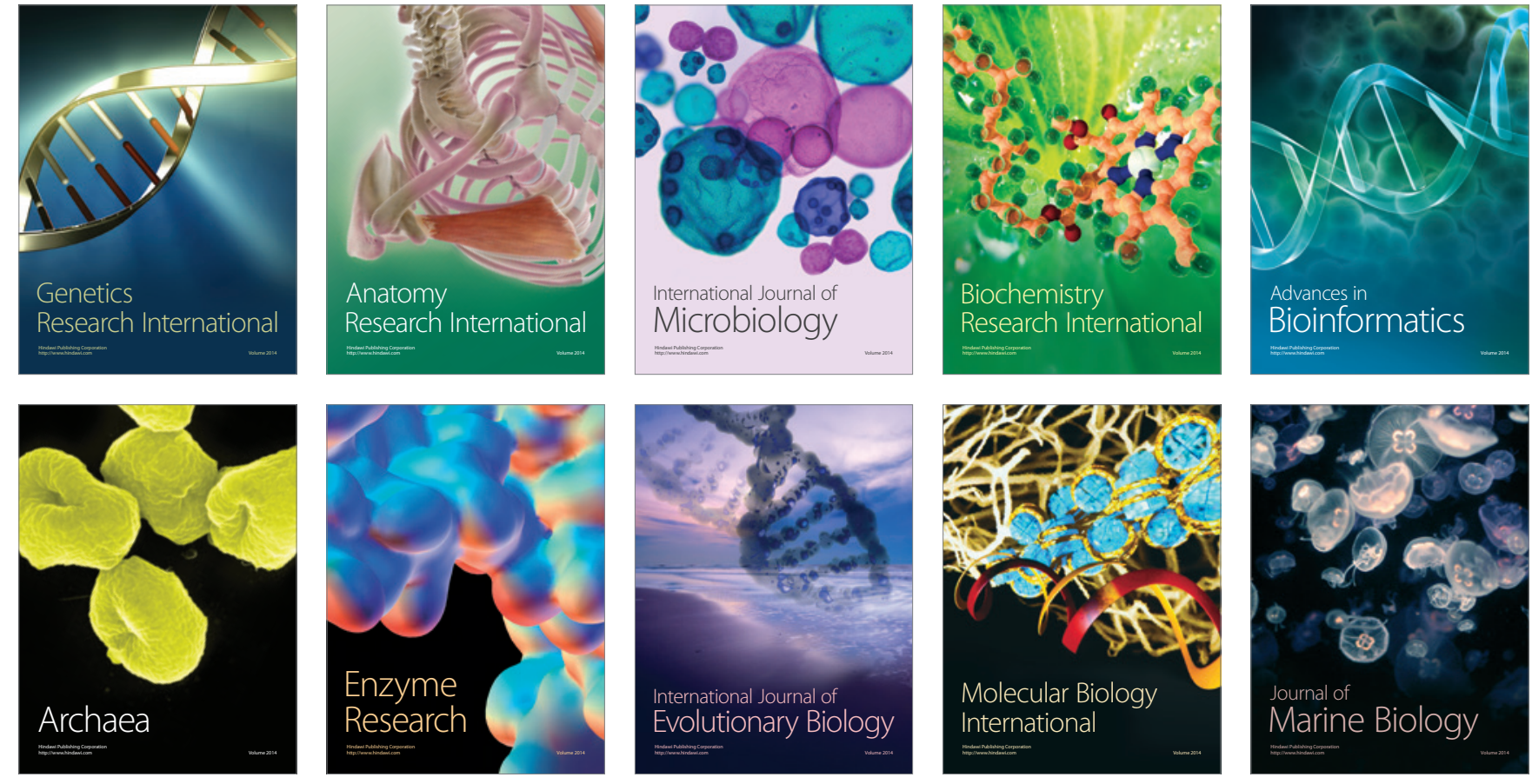